\title{
Capítulo 3 \\ Cinco masacres ocurridas en la región: contexto jurídico
}

\author{
Edward Salazar* \\ Francisco Parra** \\ Sady del Valle*** \\ Germán Romero**** \\ María Antonia Alfonzo*****
}

* Sociólogo de la Universidad Nacional y magíster en Estudios Culturales de la Universidad de Los Andes.

** Abogado de la Universidad Libre de Cali.

*** Abogada de la Universidad de Antioquia y especialista en Derecho Procesal de la Universidad de Cartagena.

**** Abogado. Especialista en Ciencias Penales y Criminología. Candidato a magíster en Derecho de la Universidad de Cartagena.

***** Abogada, especialista en Derecho Penal, Derechos Humanos y DIH aplicado a los conflictos. Teniente de Fragata de la Armada Nacional. 

Este capítulo aborda cinco casos de acción de grupos de Autodefensas Unidas Ilegales ${ }^{1}$ en la región de Montes de María que derivaron en masacres, diferentes tipos de violencias, estigmatizaciones, desplazamientos y otros suplicios cometidos especialmente contra la población civil. También trata las acciones tomadas por parte de la Armada Nacional en el contexto en el que ocurrieron los hechos, desde la perspectiva del desarrollo jurídico posterior a dichas masacres que enlutan la historia nacional. Se trata de casos emblemáticos para Colombia en el compromiso de reparación, verdad y no repetición. Dichos casos seleccionados son masacres ocurridas entre los años 1996 y 2001, en los siguientes territorios de la región: Pichilín (1996), Capaca (1999), El Salado (2000), Mampuján (2000) y Chengue (2001).

La reconstrucción de los casos desde la perspectiva jurídica se entiende como la trazabilidad del proceso legal que, en el marco de los diferentes sistemas de justicia, se adelantó en relación con las personas, entidades y estructuras involucradas en la comisión de los hechos delictivos. Para conseguirlo, este capítulo se basa en los documentos oficiales derivados de procesos legales en sentencias penales y administrativas falladas en contra o a favor de las

1 Como se ha mencionado anteriormente, "paramilitares" es el término que se ha utilizado en los medios de comunicación, informes, investigaciones académicas y en algunos procesos judiciales adelantados, entre otras fuentes. Sin embargo, el término no se considera pertinente, pues da a entender que se trata de una fuerza paralela o similar a la militar del Estado. Por ello se llaman, en adelante, autodefensas ilegales para hacer referencia a los grupos paramilitares. Adicionalmente, la Ley 975 de 2005 en el artículo segundo no se usa la palabra paramilitar, pues son llamados "grupos armados organizados al margen de la ley", en los que incluyen los grupos guerrilleros y autodefensas y sus partes significativas. 
personas involucradas, tanto de las estructuras de las autodefensas ilegales como de los miembros de la Armada Nacional. Contempla, además, datos generales de la ocurrencia de los hechos, así como una lectura de alcance contextual que matice y permita encontrar luces de análisis del accionar de los actores ilegales y las operaciones de la Armada.

Hay que tener en cuenta que el material probatorio con el que se basa la justicia para tomar sus decisiones es producto de un proceso de investigación histórica y de reconstrucción de los hechos desde la visión de la búsqueda de la verdad, con todas las limitaciones y posibilidades que esta expresión puede contener. Así, antes de entrar en el abordaje jurídico de los cinco casos, es necesario presentar un breve panorama de las operaciones de la Armada y de las acciones de las autodefensas ilegales en la región para el periodo de comisión de las masacres.

No puede iniciarse una lectura de los hechos sin contemplar las posibilidades operativas relacionadas con las limitaciones y repertorios técnicos y tecnológicos en clave histórica, así como el propio desarrollo de los marcos jurídicos.

Tras un contexto de intensa violencia y recrudecimiento de la violencia en relación con la aparición del narcotráfico y el robustecimiento de la acción de las autodefensas, en 1991 se relegitimó la defensa de la población civil por medio del uso de las armas por entes particulares y privados en los territorios. Esta decisión se dispuso en el artículo $9^{\circ}$ del Decreto Ley 2535 de 1993, por medio de la cual se le dio sustento jurídico a las denominadas Convivir, que se articularon dentro del panorama nacional amparadas por la norma como servicios especiales de vigilancia y seguridad privada. Fueron legitimados a su turno en la Ley 356 de 1994 y por la Resolución 368 de 1995 de la Superintendencia de Vigilancia y Seguridad Privada, que finalmente da nombre a esta estructura armada.

Este conjunto de normas resultó excesivamente permisivo para el surgimiento y establecimiento de grupos paraestatales erróneamente legitimados desde la necesidad de seguridad territorial (monopolio que le debería corresponder exclusivamente al Estado), en donde el porte justificado de armas fue altamente problemático en tanto debería ser de uso privativo de la Nación. Entre las consecuencias se lista el permitir a privados tomar decisiones 
y emprender acciones violentas desde el uso de la fuerza, con el agravante de que las autodefensas desdibujaron sus mentados intereses iniciales de protección de la legitimidad del Estado, pasando a conformar grupos de autodefensas ilegales en contra de la propia autoridad estatal. Lo hicieron, además, con el beneplácito de otros actores con los que

los grupos de autodefensas presentes en la subregión Montes de María realizaron acciones focalizadas en el área baja del territorio ${ }^{2}$, con el fin de generar medidas coercitivas que facilitaran la adquisición de tierras de utilidad para las rutas del narcotráfico, parte de estas actividades fueron realizadas en mutuo acuerdo con políticos regionales y miembros corruptos de la Fuerza Pública. (Reyes 2011: 50)

Este tipo de políticas y de intereses privados con lógicas perversas y de beneficio individual recrudecieron el conflicto armado, facilitaron las recurrentes violaciones de derechos humanos y fomentaron la conformación de grupos de autodefensas ilegales fortalecidos y al margen de la ley. También complicaron las posibilidades de acción de la Armada Nacional, pues se fortaleció a un actor no estatal al dotarlo de marco legal y armas (además del patrocinio de actores políticos y económicos), aumentando posteriormente un antagonismo respecto al control territorial y defensa de la población difícil de combatir. Esto hay que leerlo también en el contexto del tránsito de la administración de justicia de un sistema penal inquisitivo como el que regía el Decreto 2700 de noviembre 30 de 1991 del Código de Procedimiento Penal vigente a la fecha, a uno de tendencia acusatoria (que se implementó en el marco del Plan Colombia).

Se suma también el que la Armada Nacional no poseía, para la época, infraestructura amplia y suficiente en cuanto a comunicaciones, transporte, armamento y tecnología como la que existió posteriormente. Cita de ello es que los aportes del Plan Colombia, en su primera fase denominado "Plan para la paz, la prosperidad y el fortalecimiento del Estado", llegaron entre los años 2000 y 2006: apenas

2 Ribera del río Magdalena, San Antonio de Palmito, Toluviejo y las zonas costeras de Tolú y San Onofre. 
un año al tiempo de la ocurrencia de los casos estudiados. Dicho Plan centró sus esfuerzos en fortalecer las capacidades técnicas y operativas de la Fuerza Pública, así como en apoyar la implementación del sistema penal oral acusatorio que rige actualmente a través de la Ley 906 de 2000 (Departamento Nacional de Planeación, 2016:1).

Así, para el periodo de las masacres estudiadas y antes de la puesta en marcha del Plan Colombia, la Armada no contaba con la misma dotación técnica y de recursos que fue posible después de la entrada en vigencia del citado Plan Colombia. Estos hechos son fundamentales para la reconstrucción histórica, pues como se verá en cada uno de los casos, los elementos técnicos y operativos se relacionaron de manera decisiva con las acciones posibles en los territorios.

Para el año 200o, la jurisdicción terrestre de la Armada Nacional en el Caribe (que incluye la región de Montes de María) a cargo de la Primera Brigada de Infantería de Marina fue de $14875 \mathrm{~km}^{2}$. Dentro de esta configuración, la región de Montes de María se encuentra en el centro de dos carreteras principales que comunican a las ciudades de Sincelejo (Sucre) y Cartagena (Bolívar), que fueron las únicas vías de acceso importantes de la región. Las otras eran carreteables, es decir, transitables pero con ciertos grados de dificultad, o trochas para tránsito de vehículos tipo campero, las cuales en época de invierno dificultan significativamente la movilidad. Esta región también se caracterizó por tener caminos de herradura que en algunos sectores son camino obligado, de lo que se derivan condiciones de operación difíciles y que requieren de tiempo y entrenamiento especial para su ejecución.

De acuerdo con la información suministrada por un miembro de la Armada Nacional que en su momento hizo parte de la Primera Brigada de Infantería de Marina3 ${ }^{3}$ a la fecha de las acciones terroristas, dicha Unidad Militar contaba con 11 compañías operativas, las cuales se ubican en puntos estratégicos tratando de controlar, con todas las dificultades, los corredores de movilidad y las principales rutas empleadas por los grupos delincuenciales. Un ejemplo de ello es la no disponibilidad de helicópteros con la capacidad de realizar vuelos

3 Conversación con miembro de la Armada Nacional para la época, comunicación personal, 20 de noviembre de 2017. No se revela su identidad, por temas de seguridad y confidencialidad. 
nocturnos en la zona de Montes de María para dicho periodo, y lo que esto significa en la comisión de actos contra la población civil, sobre todo cuando se sabe que muchas de las acciones fueron adelantadas en horarios sin luz del sol.

De acuerdo con los requerimientos técnicos obligados por el protocolo de la operación, para lograr un cubrimiento efectivo de estos 85 puntos se hubieran necesitado mínimo 10 compañías más para efectuar un cubrimiento de área que garantizaran seguridad y control sobre los puntos amenazados.

Tabla III-1. Estructura de la Primera Brigada de Infantería de Marina

\begin{tabular}{|c|c|c|c|c|c|}
\hline Unidad & Oficiales & Suboficiales & $\begin{array}{c}\text { Infantes } \\
\text { de Marina } \\
\text { Profesionales }\end{array}$ & $\begin{array}{l}\text { Infantes } \\
\text { de Marina } \\
\text { Regulares }\end{array}$ & Total \\
\hline $\begin{array}{l}\text { BACIM } 33 \\
\text { Batallón de } \\
\text { Contraguerrillas }\end{array}$ & 06 & 29 & 185 & 0 & 220 \\
\hline $\begin{array}{l}\text { BACIM } 31 \\
\text { Batallón de } \\
\text { Contraguerrillas }\end{array}$ & 10 & 40 & 317 & 0 & 367 \\
\hline $\begin{array}{l}\text { BAFIM } 5 \\
\text { Batallón de Fusileros } \\
\text { de Infantería de Marina } \\
\text { No. } 5 \\
\text { Compañía Búfalo No. } 33\end{array}$ & 24 & 100 & 0 & 890 & 1014 \\
\hline $\begin{array}{l}\text { BAFIM } 3 \\
\text { Batallón de Fusileros de } \\
\text { Infantería de Marina }\end{array}$ & 10 & 28 & 0 & 360 & 398 \\
\hline Total & & & & & 1999 \\
\hline
\end{tabular}

Fuente: elaboración propia a partir de datos del Comando Primera Brigada de la Infantería de Marina (2014).

Como producto de las acciones violentas en los territorios que disminuyeron el pie de fuerza, la operación en la región dejó saldos de muertos y heridos en combate de miembros de la Infantería de Marina, cometidas por los actores ilegales del territorio. 
Figura III-1: Dispositivo Unidades Primera Brigada de Infantería de Marina

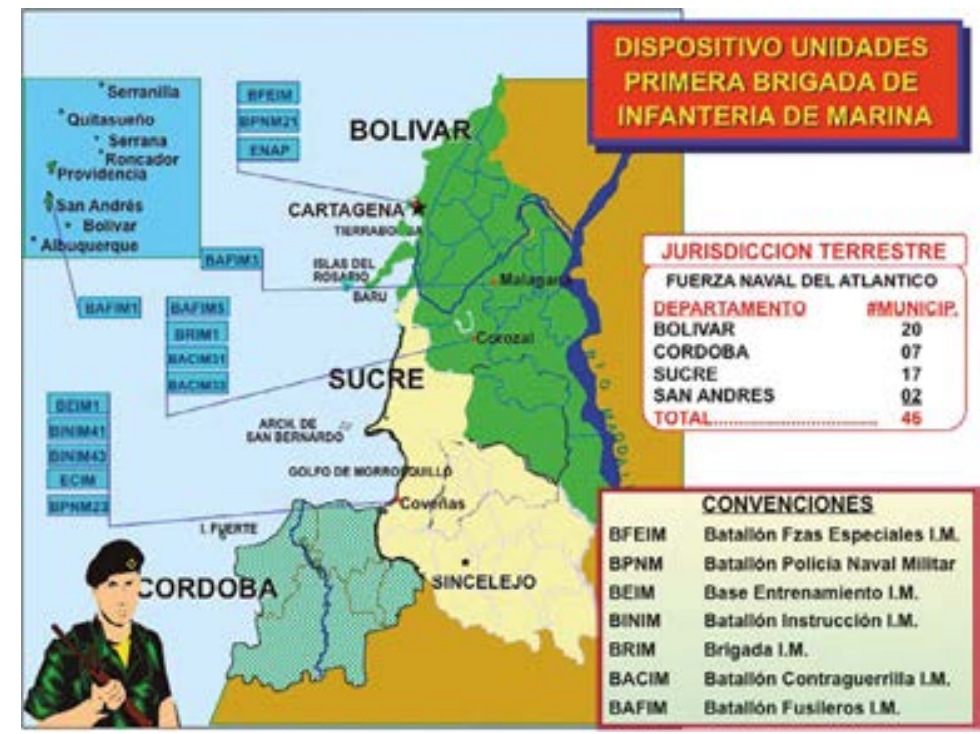

Fuente: Comando Primera Brigada de I.M. No. 1 (2014).

Tabla III-2. Acciones violentas realizadas por parte de las organizaciones ilegales

\begin{tabular}{|l|c|c|c|c|c|}
\hline \multicolumn{1}{|c|}{ Acciones de las organizaciones ilegales } & 1996 & 1998 & 1999 & 2000 & 2001 \\
\hline Civiles asesinados & 18 & 26 & 35 & 42 & 57 \\
\hline Militares asesinados & 1 & 7 & 8 & 10 & 14 \\
\hline $\begin{array}{l}\text { Enfrentamientos entre la tropa y las } \\
\text { organizaciones ilegales }\end{array}$ & 25 & 23 & 0 & 0 & 0 \\
\hline $\begin{array}{l}\text { Activación explosivos puestos por las } \\
\text { organizaciones ilegales }\end{array}$ & 7 & 5 & 10 & 14 & 14 \\
\hline $\begin{array}{l}\text { Hostigamientos por parte de las } \\
\text { organizaciones ilegales que no derivaron } \\
\text { en enfrentamientos. }\end{array}$ & 8 & 3 & 0 & 0 & 0 \\
\hline Ataques contundentes contra la tropa & 2 & 1 & 10 & 1 & 1 \\
\hline Emboscadas & 5 & 0 & 0 & 0 & 0 \\
\hline
\end{tabular}

Fuente: Comando Primera Brigada de I.M. No. 1 (2014). 
Por su parte, las autodefensas ilegales, aunque ya existían desde principios de la década de 1980, intensificaron su presencia con la llegada desde Córdoba en 1996 y 1997 de jefes pertenecientes a las autodefensas ilegales, organizados bajo las AUc. Es en esta época que ocurrieron varias masacres de campesinos estigmatizados al ser señalados como guerrilleros, se incrementaron los ataques a la población a menudo coordinados con frentes de las autodefensas ilegales, y la acción de las Fuerzas Armadas contra las guerrillas, convirtiendo veredas o aldeas de los Montes de María en verdaderos campos de batalla (PODEC, 2011: 27 y 39, citado en Lefkaditis, Patrick y Ordóñez Gómez, 2014: 51).

Las "Autodefensas Campesinas de Córdoba y Urabá", con influencia en las regiones de Antioquia, Córdoba y Chocó, son un solo ente al margen de la ley que formó parte del denominado "Proyecto Nacional Autodefensas Unidas de Colombia”, dirigidas por Salvatore Mancuso. Esta configuración de actores ilegales fortalecidos por diferentes medios dio como resultado el que se efectuaran en la zona

\begin{abstract}
[...] un total de 207 ataques terroristas, y para el mismo periodo se presentaron 41 acciones subversivas, generándose para ambos casos un aumento significativo durante el periodo 2002-20034. Estos actos delictivos inmersos en un ambiente de conflicto, donde no se evidenciaba acciones contundentes por parte de la Fuerza Pública, dieron pie para que ganaderos, terratenientes y políticos locales impulsaran las Autodefensas Ilegales, quienes iniciarían una campaña por las zonas estratégicas del territorio, señalando miembros de la población civil de ser colaboradores de la guerrilla, e implementando las masacres como mecanismo de terror. (Reyes, 2011: 55)
\end{abstract}

Estas acciones fueron perpetradas en su mayoría, para los casos de estudio, por el Bloque Norte Frente Rito Antonio Ochoa (dentro del que se encuentran las autodefensas ilegales Bloque Héroes Montes de María) con actuación en la región, estaba conformado de la siguiente manera:

4 DNP, Cifras de Violencia Montes de María 2002-2005, pp. 2-7. 
Tabla III-3. Estructura de los grupos de autodefensas ilegales Bloque Norte, Frente Rito Antonio Ochoa

\begin{tabular}{|c|c|c|c|}
\hline Grupo & Cabecilla & Fuerza & Zonas de influencia \\
\hline $\begin{array}{l}\text { Grupo San } \\
\text { Onofre }\end{array}$ & $\begin{array}{l}\text { Rodrigo } \\
\text { Antonio } \\
\text { Mercado } \\
\text { Pelufo (alias } \\
\text { 'Cadena') }\end{array}$ & $\begin{array}{l}200 \text { hombres } \\
\text { en armas }\end{array}$ & $\begin{array}{l}\text { San Onofre, Tolú, Toluviejo, Ovejas, Chalán } \\
\text { y Palmitos (Sucre); Lorica, Momil y San } \\
\text { Bernardo del Viento (Córdoba), y con } \\
\text { presencias esporádicas en los corregimientos } \\
\text { de Macayepo y Cansona, jurisdicción del } \\
\text { municipio de Carmen de Bolívar. }\end{array}$ \\
\hline $\begin{array}{l}\text { Grupo Guamo / } \\
\text { Calamar }\end{array}$ & $\begin{array}{l}\text { Rafael } \\
\text { Gregorio Ávila } \\
\text { Jiménez (alias } \\
\text { 'Serpa') }\end{array}$ & $\begin{array}{l}150 \text { hombres } \\
\text { en armas }\end{array}$ & $\begin{array}{l}\text { San Jacinto, San Juan Nepomuceno, El Guamo, } \\
\text { Calamar, Mahates, Villanueva (Bolívar), Plato y } \\
\text { Tenerife (Magdalena). }\end{array}$ \\
\hline $\begin{array}{l}\text { Grupo María } \\
\text { la Baja / Canal } \\
\text { del Dique }\end{array}$ & $\begin{array}{l}\text { Uber Enrique } \\
\text { Bánquez } \\
\text { Martínez } \\
\text { (alias } \\
\text { 'Juancho' } \\
\text { Dique*-Fredy } \\
\text { - Leonardo) }\end{array}$ & $\begin{array}{l}250 \text { hombres } \\
\text { en armas }\end{array}$ & $\begin{array}{l}\text { San José del Playón, Retiro Nuevo, Arroyo } \\
\text { Hondo, Níspero, Matuya, El Puerto, Correa, } \\
\text { Ñanguma, Mampuján, Flamenco y San Pablo, } \\
\text { jurisdicción del Municipio de María la Baja } \\
\text { (Bolívar); Rocha y Puerto Badel, jurisdicción } \\
\text { del municipio de Arjona; Cañaveral, } \\
\text { jurisdicción del municipio de Turbaco; } \\
\text { Ballesta, jurisdicción del municipio de } \\
\text { Ballesta; San Basilio de Palenque y Malagana, } \\
\text { jurisdicción del municipio de Mahates } \\
\text { (Bolívar); La Haya y San Cayetano, jurisdicción } \\
\text { de San Juan de Nepomuceno y San Cristóbal y } \\
\text { Paraíso, jurisdicción Municipio de San Jacinto } \\
\text { (Bolívar). }\end{array}$ \\
\hline $\begin{array}{l}\text { Grupo } \\
\text { Zambrano }\end{array}$ & $\begin{array}{l}\text { Alias 'el } \\
\text { Cacique } \\
\text { Montoya' }\end{array}$ & $\begin{array}{l}70 \text { hombres } \\
\text { en armas }\end{array}$ & $\begin{array}{l}\text { Carmen de Bolívar, Zambrano y Córdoba } \\
\text { (Bolívar); Sincé, Galeras, Buenavista y San } \\
\text { Pedro (Sucre). }\end{array}$ \\
\hline
\end{tabular}

* Fundación Seguridad de Democracia Desmovilización del Bloque Héroes de Montes de María de las AUC, Juan Carlos Garzón Investigador Asociado a la fundación.

Fuente: elaboración propia a partir de datos del Comando Primera Brigada Infantería de Marina (2014).

En la jurisdicción de la Primera Brigada de I.M., este grupo contaba aproximadamente con 670 sujetos divididos en cuatro grupos (San Onofre, El Guamo/Calamar,Zambrano/Córdoba y María La Baja o Canal del Dique) y un considerable número de colaboradores, dirigidos por Úber Enrique Bánquez Martínez (alias 'Juancho Dique', alias 'Fredy' o 'Leopardo'), los cuales hacían parte del Bloque Norte de las AUC. El grupo estuvo conformado en su gran mayoría por reservistas 
de diferentes unidades de las Fuerzas Militares, generalmente oriundos de los departamentos de Antioquia, Córdoba y Atlántico.

El Bloque Montes de María (desmovilizado el 14 de julio de 2005) fue creado en 1997 por un grupo de empresarios y políticos locales junto a los hermanos Castaño y Salvatore Mancuso (ver capítulo "Dinámicas de la violencia en Montes de María"), con el fin de captar los espacios que hasta el momento ocupaban las FARC y el ELN, así como para obtener el control sobre el tráfico de drogas y armas en el golfo de Morrosquillo. Dichas autodefensas ilegales estuvieron conformadas por el Frente Canal del Dique, quienes aterrorizaron a la población civil con masacres como la de Mampuján (2000) y Chengue (2001). El grupo estuvo al mando de Rodrigo Mercado Peluffo, alias 'Cadena', y Edwar Cobos Téllez, alias 'Diego Vecino'.

Dichos grupos de las autodefensas ilegales, a diferencia de las fuerzas del Estado, actúan por fuera de márgenes en los que la vida humana es el valor fundamental a proteger y garantizar, y al contrario utilizan la vulneración de la vida como un elemento de poder y de reafirmación en los territorios. Este mecanismo de control terrorista permite que el despliegue de las acciones tenga menos restricciones en su ejecución, pues si bien contaban con un pie de fuerza menor que el que tenía la Armada, actuaron de modo tal que esta capacidad no fuera un impedimento. Esto quiere decir que ambos actores tuvieron repertorios de acción diferenciados en donde el Estado, al contrario, debe garantizar la vida, la seguridad y la libertad de las personas. Dicha diferenciación es clave a la hora de tener en cuenta que la Armada Nacional no puede actuar indiscriminadamente contra la vida, sino que justamente incluso al desplegar acciones en las que se emplea el control de la vida contra los agentes paraestatales debe hacerlo dentro de un marco legal, operacional, técnico y logístico que limita su acción. También se puso en riesgo la vida de las personas al servicio de la Armada Nacional, vidas que también había que cuidar y poner en acción de acuerdo con las posibilidades de éxito que la institución pudiera tener.

No quiere decir, sin embargo y como se verá en el desarrollo de las masacres, que personas individuales al servicio de las fuerzas de Estado no hubieran actuado en contra de la lógica de la garantía de la vida y la protección a la población civil, pues desconociendo el deber esencial del Estado actuaron por fuera de su margen misional. Bajo 
este panorama complejo ocurrieron las cinco masacres que se abordarán desde la perspectiva jurídica, con el fin de brindar elementos de lectura para el trasfondo de la situación de operación, responsabilidad y/o posibilidad de la Armada Nacional. Los casos serán presentados en orden cronológico.

\section{Pichilín: 4 de diciembre de 1996}

\section{Hechos}

La masacre de Pichilín fue la primera cometida por las autodefensas ilegales en el departamento de Sucre. El jefe de la unidad policial Subteniente Giovanny Madariaga Pérez, informó de los hechos ${ }^{5}$ el 4 de diciembre de 1996 en horas de la tarde, aproximadamente a las 4:30, en el corregimiento de Pichilín, ubicado en la zona rural del municipio de Morroa (Sucre). Allí, un grupo de 50 hombres de las Autodefensas Unidas de Córdoba y Urabá, algunos de ellos utilizando uniformes camuflados, otros de la Policía Nacional y el resto de civil, ingresó a la zona. Lo hicieron en 10 vehículos inmovilizados previamente durante un retén realizado frente a la finca La Llave, ubicada en inmediaciones del municipio de Morroa. Las autodefensas ilegales se ubicaron en el centro del pueblo donde citaron a toda la población y posteriormente ordenaron que los hombres permanecieran, mientras que las mujeres y los niños fueron llevados hacia el puesto de salud.

Seleccionaron 12 hombres $^{6}$ a los que señalaron de colaborar con la guerrilla. Los amarraron y tiraron al suelo boca arriba. Dentro del pueblo fueron asesinadas 2 personas, y las restantes subidas a los vehículos que partieron hacia la carretera que conduce de Tolú Viejo a la Cementera, donde fueron asesinadas y dejadas a lo largo de la vía. Los testigos Francisco Enrique Villalba Hernández, Ramiro Enrique

5 Reposa en el plenario el Oficio 0445 proveniente de la sıIN de Sucre fechado 5 de diciembre de 1996, suscrito por el jefe unidad policía judicial ST Giovanny Madariaga Pérez.

6 Manuel Vicente Vergara Villalba, Israel Remberto Vergara Puche, Luis Eduardo Salgado Rivera, Emiro Rafael Tovar Rivera, Eberto Segundo Tovar Zequea, Jorge Luis Torres Cuello, Federmán Rivera Salgado, Ovidio Castillo, José Daniel Rivera Cárdenas, Manuel de Jesús Pérez Gómez, Germán Ulises Ramos Mercado y Jesús Alberto Pérez Rodríguez. 
Salgado, Francisco Ramos Mercado, Guillermo Narváez García, entre otros7, dicen que llegaron con una lista en la que estaban previamente señalados los nombres de las 12 víctimas.

Los victimarios, que utilizaron armas cortas y largas, eran integrantes de las Convivir (en ese momento avaladas por el Estado) Nuevo Amanecer y Nuevo Horizonte, dirigidas por Javier Piedrahíta y Salvatore Mancuso. Mancuso, quien admitió su participación en los hechos, vinculó este acto a miembros del Ejército, la Infantería de Marina y la Policía en Sucre a los que señaló de conocer los planes con anterioridad y despejaron la vía para la llegada de las Autodefensas. También consta en el expediente (Juzgado Penal del Circuito Especializado, Sincelejo, Sucre, 7 de junio de 2002) que los victimarios prendieron fuego a varios lugares en los que llegaron y robaron prendas y dinero de algunos habitantes. Manifestaron estar realizando una "limpieza" y dejaron letreros como advertencias: "Muerte a sapos colaboradores de las Farc" (Juzgado Penal del Circuito Especializado, Sincelejo, Sucre, 7 de junio de 2002).

\section{Desarrollo judicial}

En este proceso fueron investigados Francisco Enrique Villalba Hernández ${ }^{8}$, Capitán de Infantería de Marina Jorge Javier Muñoz Suárez, Mayor de la Policía Luis Guillermo Parra Niño (miembro de la Policía Nacional), Salomón Feris Chadid, Jorge Miguel Baquero Tuirán, Rafael Eduardo Vergara Vivero, Jerónimo Enrique Bonett Mogollón, Dayro de Jesús Vargas Cardona y Alejandro Morelo Pérez.

\section{Hacia los actores ilegales}

En declaración, Álex Conde Anaya sostuvo que la masacre fue planeada por el señor Salomón Feris Chadid y Salvatore Mancuso, alias el 'Mono' o ‘Triple Cero'. Señaló que el señor Feris Chadid estaba

7 Sentencia primera instancia proceso 2001-0034 del juzgado penal del circuito especializado de Sincelejo.

8 Asesinado en 2009. http://www.semana.com/opinion/articulo/daniel-coronell-el-hombreque-sabia-demasiado/417154-3 
encapuchado al momento de los hechos, y quien señalaba a las víctimas era Pedro Carvajalino. En su intervención ante el juzgado, Villalba Hernández manifestó que Feris Chadid lo buscó para realizar un operativo en Pichilín: dice que salieron el 2 de diciembre a las 12 de la noche para Palmira donde se encontraron en una finca en la parte de atrás del caserío con un grupo de cuarenta hombres al mando de 'el Mono Mancuso'.

Dentro de la diligencia de indagatoria que se tuvo en cuenta para emitir la sentencia de primera instancia (Proceso 2001-00034), Salomón Feris Chadid manifestó que se enteró por la prensa de que lo acusan de ser jefe de un grupo de autodefensas ilegales, y aseguró que cuando el Gobierno dio lugar a las Asociaciones Cooperativas de Seguridad Privada (Convivir) conformó una de ellas, "Orden y Desarrollo", de la que era el coordinador y receptor de todo tipo de información. En ella el accionar era legal toda vez que el Estado promovió este tipo de asociaciones. Para la década de los noventa cuando se crearon las Convivir, las autodefensas campesinas de Córdoba y Urabá, participó Salomón Feris Chadid, conocido en el departamento de Bolívar y Sucre como ganadero reputado (El paramilitar Salomón Feris Chadid: "El Señor de Santa Fe Ralito", 2008).

Retomando la diligencia de indagatoria rendida, Feris manifestó que para el día de los hechos permaneció en un taller de mecánica, impidiéndole estar en el lugar que se le indica. Aseguró que se enteró de estos hechos por la prensa y televisión y niega rotundamente haber participado. En ampliación de indagatoria, Francisco Enrique Villalba Hernández señaló que para realizar este acto le fue entregado un revólver 38 corto, perteneciente a Salomón Feris, con el cual disparó a su familiar Manuel Vergara.

El juzgado especializado de Sincelejo consideró que la confesión judicial de Francisco Enrique Villalba Hernández y las pruebas que lo avalaron dan total credibilidad, pues la veracidad de las circunstancias de tiempo, modo y lugar llevaron al juzgado a declarar con absoluta certeza la responsabilidad penal de Villalba Hernández, pues tratándose de un miembro del grupo al margen de la ley tuvo el detalle de los acontecimientos anteriores y posteriores al hecho.

El Juzgado Penal del Circuito Especializado de Sincelejo el 7 de junio del 2002 le dictó sentencia por los delitos de homicidio agravado en concurso con los delitos de utilización ilícita de los equipos de transmisores o receptores; utilización ilegal de uniformes e 
insignias de las fuerzas militares; secuestro de aeronaves, naves y otros medios de transporte colectivo; sentencia condenatoria como coautor por los delitos antes descritos a una pena principal de prisión de cuatrocientos meses, es decir, 33 años y 4 meses y por último una multa de 1667 salarios mínimos legales mensuales vigentes para el año 1996 a favor del Tesoro Nacional. Se condenó a Villalba Hernández a la pena accesoria de interdicción de derechos y funciones públicas por un periodo de 10 años, a pagar por concepto de daños y perjuicios morales la cantidad de 800 salarios mínimos legales mensuales por cada víctima.

En sentencia del 29 de mayo de 2003, el Tribunal del Distrito Judicial de Sincelejo, en Sala Plena con Magistrado Ponente Lucy Bejarano Maturana, resolvió el recurso de apelación interpuesto por el defensor de Francisco Enrique Villalba Hernández, a la sentencia proferida por el Juzgado Penal del Circuito Especializado de Sincelejo, quien confirmó el fallo de primera instancia como autor responsable de los delitos de homicidio agravado en concurso heterogéneo, utilización ilícita de equipos transmisores o receptores, utilización ilegal de uniformes e insignias y apoderamiento de aeronaves, naves o medios de transporte colectivo.

Villalba Hernández ${ }^{9}$ admitió ser miembro de las autodefensas ilegales desde 1994, ser un reclutado por Salomón Feris Chadid, y reconoció haber participado en la matanza de Pichilín, en donde le correspondió disparar a personas de su familia. El 29 de mayo de 1998 se le dictó medida de aseguramiento (detención preventiva sin beneficio de excarcelación) por homicidio con fines terroristas, concierto para delinquir, utilización ilícita de equipos de transmisión y receptores, así como utilización ilegal de uniformes e insignias, porte ilegal de armas de fuego, tortura, daño en bien ajeno, hurto calificado y agravado, incendio con el agravante de que la conducta fue realizada en establecimientos públicos. Mediante Resolución de 7 de diciembre de 1999 se modificó la anterior decisión en el sentido de aclarar que la medida de aseguramiento impuesta como autor y

9 La acusación fue remitida al Juzgado Penal del Circuito Especializado de Sincelejo en donde se aprehende el conocimiento el 11 de septiembre de 2001. El Juzgador de primera Instancia dice que se entregó en forma voluntaria el 13 de febrero de 1998 en el municipio de Santa Rosa de Osos-Antioquia, y consideró que la confesión es digna de total credibilidad y condujo a Villalba a confesar. 
presunto responsable de infracción al Decreto 1194/89 (artículo 2) que fue consagrado como legislación permanente por el Decreto 2266 de 1991 (artículo 6), para aclarar que por favorabilidad no se tuvo en cuenta lo señalado en la Ley 365 de 1997, ya que la ocurrencia de los hechos se remonta al 4 de diciembre de 1996. También se precluyó la investigación por los delitos de tortura e incendio.

El Ministerio Público manifestó que el procesado al reconocer abiertamente la participación en los hechos investigados se le pueden endilgar al menos dos de los homicidios que el material probatorio confirma. Por ello solicitó que la sentencia recurrida se mantuviera por estar ajustada a derecho.

La sala consideró que la tipicidad de las conductas atribuidas a Francisco Enrique Villalba Hernández no admitía discusión, pues los hechos descritos produjeron la muerte de varias personas. Manifestó que está en discusión la confesión de Villalba, en cuanto a que genera la certeza necesaria para declararlo responsable como coautor de los hechos investigados. Se ha dicho que la confesión es el reconocimiento que hace el acusado del hecho que se investiga, y una vez realizada se debe hacer lo necesario para determinar su veracidad; bajo este principio, para la Sala en ningún momento fue posible demostrar que lo confesado encaja con la realidad probatoria. Muchos fueron los testimonios que llevaron a la contradicción del confeso, pues las imprecisiones que se advirtieron en este se vieron respaldadas por la prueba técnica de necropsias de los cadáveres del tío Manuel Vergaray el primo Israel Vergara. Se encontró que no coincidían las lesiones descritas por el médico legista con lo que manifestó Villalba al momento de rendir la indagatoria y sus ampliaciones. El tribunal reconoció la trascendencia de la retractación frente a sus acusaciones a terceros y de su misma autoincriminación, declarándose inocente.

El Estado de derecho exige que el sentenciador al condenar debe basar esta en una prueba que produzca certeza del hecho y certeza de la responsabilidad del procesado, y tal como la sala plena manifestó que de los hechos ocurridos no hay duda, pero que de la responsabilidad del procesado basada en su confesión no se puede predicar lo mismo, pues no resistió el análisis de su sinceridad y espontaneidad. No se alcanzó la fuerza probatoria para sustentar una sentencia condenatoria. Por ello se revocó el fallo de primera instancia y se declaró no responsable a Francisco Enrique Villalba Hernández. 


\section{Hacia la Armada Nacional}

En lo relacionado con el Capitán de la Infantería de Marina Jorge Javier Muñoz Suárez, a quien la Fiscalía profirió Resolución de Acusación del 25 de mayo del 2000 como partícipe en los delitos de homicidio agravado y otros, el despacho judicial consideró que la Fiscalía que adelantó la investigación de la Unidad de Derechos Humanos tomó como fundamento probatorio varios testimonios con la modalidad de reserva de identidad, pasando por alto la sentencia del 6 de abril de 2000 en donde la Corte Constitucional los declaró inexequibles, quedando solamente como fundamento de esa acusación los testimonios de Francisco Enrique Villalba Hernández y Pedro Álex Conde Anaya. La Fiscalía consideró que la participación de Muñoz Suárez era un actuar omisivo o permisivo y, en testimonio, Conde Amaya manifestó que luego de adelantar contactos en Bogotá se presentó voluntariamente ante la Fiscalía General de la Nación bajo el argumento de haber sido amenazado de muerte.

Cuando la Fiscalía lo interrogó por las relaciones del grupo de autodefensa con las fuerzas del Estado, en ningún momento hace incriminación en contra de ningún jefe de organismo de Policía Judicial o la Armada Nacional; mucho menos se refiere a la Infantería de Marina, ni al nombre de Jorge Javier Muñoz Suárez. Pero en preguntas posteriores sobre un tema diferente hace referencia a los operativos conjuntos realizados con la Convivir y la Infantería de Marina, más específicamente refiriéndose al Capitán Muñoz. Es claro que no tenía conocimiento directo, pues no podía discernir sobre la identidad del Capitán.

Esa diligencia se suspendió y se reinició horas más tarde. Cuando se le hizo la pregunta referente a los comandantes de cada grupo, manifestó que el comandante del grupo de Infantería de Marina era el señor Jorge Muñoz Suárez, jefe de la sección de operaciones del B2 de la Primera Brigada de Infantería de Marina de Sincelejo-Sucre. Manifestó también que en reuniones previas a la masacre el Capitán Muñoz se reunió en la finca "Quinitén” en compañía del "mono" y Salomón. Sin embargo, en otra intervención se contradice diciendo que esa reunión se realizó en un restaurante a la salida de Sincelejo que conduce a Corozal, pero que no recuerda el nombre. Ahí, señala, se planeó todo lo relacionado con la masacre. En otra ocasión, refiriéndose a los mismos hechos dijo que a ese sitio también llegaron 
las personas apodadas 'Lino’ y ‘Toni', entre otras personas, de las cuales no recordaba ni los nombres ni los alias. También dice que en otra parte en la que se coordinó la masacre fue el despacho del jefe de la Sijín de Sincelejo, Mayor Parra Niño, en donde se reunieron el Mayor, Salomón y él. En otra declaración dice que esta reunión previa se realizó en la casa de Salomón, en donde asistieron el Capitán Muñoz, el Mono, Salomón y muchas personas más. El despacho consideró que estas aseveraciones carecían de credibilidad.

Sobre la participación de Muñoz Suárez, manifestó que se había comprometido a despejar la vía del peaje que conduce de Sincelejo a Toluviejo, y así mismo dijo que la Policía quitó el retén que por costumbre ubica en la bomba y la Infantería levantó los puestos de control, afirmaciones sostenidas por el testigo en varias de sus intervenciones. El declarante no conocía la realidad en donde el señor Jorge Javier Muñoz Suárez, para la fecha de los hechos (2 al 6 de diciembre) se encontraba haciendo un curso de inteligencia en la Escuela de Guerra Anfibia. Por ello, al estar el Capitán Muñoz Suárez en dicho curso en Coveñas, no podía tener bajo su mando y órdenes a ningún personal de la Primera Brigada de Infantería. A esta conclusión llegó el titular del despacho judicial que dejó plasmado en la parte resolutiva de la sentencia. El declarante Conde Anaya manifestó que él siempre se mantenía acompañado de unas personas apodadas 'el gato’ y 'el paisa', por la desconfianza que le tenían el mono Mancuso y Salomón Feris, siendo así que no era una persona de confianza dentro de las autodefensas ilegales, de donde iba a obtener una información verdadera de las operaciones que estos realizaban, quedando en entredicho cada una de sus intervenciones y las acusaciones que lanzaba sobre otras personas.

En la investigación penal en contra de Muñoz Suárez también existen declaraciones de Carlos Armando Bernal Sánchez, quien manifestó que el día primero de diciembre estaba en la Base de Entrenamiento de Infantería de Marina de Coveñas prestando guardia y ese día vio al Teniente Muñoz Jorge, quien ingresaba a la base para recibir un curso de inteligencia en la Escuela de Guerra Anfibia. Esta declaración coincide con la declaración hecha por Luis Alfonso Lerma Solís dentro del mismo proceso.

En el numeral séptimo de la sentencia del Juzgado Penal del Circuito Especializado del 7 de junio del 2002, se absolvió de la responsabilidad penal al Capitán Jorge Javier Muñoz Suárez. 


\section{Contexto de la acción}

Según Salvatore Mancuso, quien admitió la responsabilidad por estos hechos (y que hacía parte del plan de expansión de las Accu en territorios claves para el negocio del narcotráfico), las autodefensas ilegales contaron con el apoyo de miembros del Ejército, la Infantería de Marina y la Policía en Sucre, pues no solo conocían los planes previamente, sino que despejaron la vía para la llegada del grupo armado. A pesar de ello, ningún miembro de las Fuerzas Armadas ha sido condenado por estos hechos, pues, como se vio anteriormente, el Capitán de la Infantería de Marina Jorge Javier Muñoz fue descartado de los hechos antes las pruebas contradictorias y poco fiables de los declarantes.

Igualmente, Salvatore Mancuso aseguró haber ordenado la masacre motivado por las acusaciones de Salomón Ferris Chadid, alias '08', quien era el encargado de mantener relaciones con la fuerza pública en el municipio. Según las autoridades, en cercanías la población de Pichilín se encontraba un campamento del frente 35 de las FARC. Mancuso aseguró haber asistido a una reunión el 2 de diciembre, dos días antes de la masacre, en la que explicó al Mayor Luis Guillermo Parra Niño de la Sijín de Sincelejo sobre la toma que las autodefensas ilegales que pretendían realizar. Las órdenes eran claras, las autoridades debían despejar la vía y no debían reaccionar bajo ninguna circunstancia en contra de las tropas de las autodefensas (La masacre de Pichilín, Sucre, s.f., párr. 1-2).

Para la fecha de la masacre (4 de diciembre de 1996), la Armada Nacional conocía la existencia de las Convivir autorizadas por el Estado, pero desconocían con precisión las acciones delincuenciales que podían desarrollar relacionadas con el caso de estudio. Sin embargo, para esta misma fecha las Convivir no existían en el territorio de Sucre. Tanto es así que quienes cometieron la masacre fueron las Autodefensas Campesinas de Córdoba y Urabá, “Accu”, lo que suponía un desplazamiento desde otro punto, lo que dificultaba la predicción de su actuación por parte de la Fuerza Pública.

Así mismo, por estos hechos el Consejo de Estado, mediante fallo del 9 de julio de 2014, profirió la reparación integral, restitución de tierras y la realización de una ceremonia pública donde la Armada Nacional y la Policía Nacional de Colombia ofrecieran disculpas a la comunidad en general por la responsabilidad que tuvieran en este 
hecho, además de colocar una placa conmemorativa a las víctimas. El Consejo de Estado condenó a la Policía y la Armada Nacional a pagar más de 3000 millones de pesos a la familia de cinco campesinos que fueron asesinados en la masacre de Pichilín por parte de grupos de Autodefensa.

En este sentido, el Consejo de Estado (2014) señaló que no se comprende cómo ante la evidente y latente amenaza, las "Fuerzas Armadas"10 no hayan tomado acciones con el fin de contrarrestar el accionar ilegal y proteger a la población civil, pues, señala el Consejo, permitieron un actuar libre durante aproximadamente 4 horas sin ejercer ningún tipo de control o respuesta. El Consejo menciona que se debió a un acuerdo entre las fuerzas armadas y las AUC (Consejo de Estado, SP44333, 2014: 52). Ante esta aseveración hay que decir, en primer lugar, que el Consejo de Estado confunde la responsabilidad individual con la institucional, y no precisa a cuál institución se refiere, o si se refiere a la Armada Nacional puntualmente cuando menciona inicialmente la responsabilidad de las 'Fuerzas Armadas'. Más adelante lo imputa directamente, basados en los testimonios de Pedro Álex Conde Anaya y Manuel Enrique Villalba (Ibíd, p. 53). Se trata de una afirmación delicada basada en la reconstrucción de los hechos desde los testimonios de los jefes de las autodefensas ilegales y las mencionadas víctimas de lo ocurrido en Pichilín, pero en donde no se ha probado directamente que la Armada haya tenido un acuerdo estructural para la comisión de la masacre. El Consejo señala que la absolución del Capitán Jorge Muñoz no es prueba suficiente, pero lo cierto es que para que dicha absolución tuviera lugar, los organismos judiciales adelantaron el mismo proceso de investigación, por lo que se entiende que los hechos de una y otra investigación están coligados. Del mismo modo, hay que señalar que la reconstrucción de los hechos no depende solo de los testimonios, sino de otros factores técnicos y operacionales relacionados.

Por ello es necesario analizar las posibilidades de la acción institucional desde diferentes ángulos. Por ejemplo, las alertas enviadas por la Policía fueron a todas luces confusas; brindaron información que no permitía la toma de decisiones y la acción precisa por parte de la Armada. No quiere decir que esta entidad sea la responsable, pero

10 Expresión utilizada por el Consejo de Estado. 
muestra que los reportes de las diferentes instituciones dificultaron las acciones por no tener el nivel técnico suficiente. No contaban con los elementos necesarios para la toma de decisiones acertadas, en un contexto de riesgo y amenazas constante en donde los actores ilegales usaron la confusión como estrategia para reducir el rango de acción de las fuerzas del Estado.

No quiere decir tampoco que se desestimen los testimonios de las víctimas en el marco de la construcción de la verdad. Sin embargo, los organismos encargados de las investigaciones deben referirse de manera más precisa a acciones ilegales individuales de personas vinculadas a una determinada institución. Dichas personas tomaron decisiones individualmente para combatir al "enemigo común" (la guerrilla), alejados de la misionalidad del Estado al poner en riesgo la vida de la población civil. Basados en una relación ambigua respecto al papel de las autodefensas y su relación con el Estado para aquel momento, algunos miembros actuaron por fuera de la legalidad aprovechando su situación de poder. Sin embargo, para el caso de Pichilín el ámbito judicial no ha reportado condenas definitivas contra miembros de la Armada Nacional de Colombia, pues el Capitán Jorge Muñoz fue absuelto de la responsabilidad penal.

Por ello es importante precisar que no se puede hablar de la responsabilidad estructural de la Armada porque no era una política del mando central el actuar de la mano con los grupos al margen de la ley. Si ocurrió fue por decisiones individuales de las personas que han sido investigadas penalmente y en cada una de estas se resolvió de acuerdo a su participación en los hechos. Así, las responsabilidades penales, que son individuales, fueron impuestas y acatadas. De otro lado, está la condena administrativa impuesta al Estado, en donde si el Consejo de Estado habla de responsabilidad, es de la responsabilidad del Estado en su conjunto. En este sentido, la Armada ha ejecutado las acciones de memoria y reparación que le han sido ordenadas.

\section{Capaca: 16 de agosto de 1999}

\section{Hechos}

El 16 de agosto de 1999 en horas de la noche, ingresó a la vereda de Capaca, jurisdicción del municipio de Zambrano (Bolívar), un grupo 
de 20 miembros de las autodefensas ilegales del Bloque Montes de María, iniciando un recorrido por varias de las veredas del municipio de Zambrano, donde asesinaron a 11 personas. Al llegar a Capaca los miembros de las autodefensas ilegales asesinaron a 5 personas: algunas en sus casas, otras en las calles. Después se desplazaron a Campoalegre y allí asesinaron a tres personas más. Tomaron, finalmente, el camino hacia el Carmen de Bolívar y asesinan a 3 personas (Masacre de Capaca, s.f.: 1). El saldo fueron $11^{11}$ víctimas mortales y cuatro $^{12}$ desaparecidos.

Los habitantes se vieron obligados a huir hacia Sincelejo, Carmen de Bolívar y Zambrano. El desalojo de la población permitió a las autodefensas ilegales realizar saqueos a cultivos y animales de los campesinos.

Estuvo al frente de la masacre Sergio Manuel Ávila alias 'Caracortada', delegado por Salvatore Mancuso para expandir las autodefensas ilegales en la región de los Montes de María entre los años 1999 hasta el 2002 (fecha de su captura). De acuerdo con las declaraciones dadas por 'Caracortada', durante los hechos perpetrados en Capaca recibieron el apoyo de miembros de la Fuerza Pública, entre los que se encontraban 12 soldados bajo las órdenes del Cabo Barreto ("“Caracortada' todavía pone a llorar a los Montes de María”, s.f.).

\section{Desarrollo judicial}

\section{Hacia los actores ilegales}

El 3 de junio de 2009, el despacho 54 de Justicia y Paz le imputó a Salvatore Mancuso Gómez, cabecilla del Bloque Héroes de Montes de María, el delito de concierto para delinquir agravado, desde su ingreso hasta

11 Daniel de Jesús Arrieta Castro, Liborio Arrieta Ospina, Soraya Paola Arrieta Oviedo, María Inés o Marnet María Bolaños Causado, Ricardo José Bolaños Causado, José Arístides de la Hoz Payares, Lader de Jesús España Álvarez, Deivis Martínez Garrido, Elías Ramón Novoa Rivera, Edilberto Manuel Ochoa Ochoa y Jesús David Oviedo González.

12 Édgar Luis Castro Arrieta, Judith del Carmen Bolaños Sánchez, Arístides Monterrosa y Juan Ochoa Ochoa. 
la desmovilización en diciembre 10 de 2004, cargos que se encuentran legalizados.

El 8 de enero de 2002 en la ciudad de Cartagena miembros de la Fiscalía General y el DAS capturaron al cabecilla del Bloque Norte de las autodefensas en el departamento de Bolívar, Sergio Manuel Córdoba Ávila, alias 'el Gordo,' 'Caracortada,' 'Don Sergio' o '120', por los delitos de concierto para delinquir y homicidio. La Fiscalía 13 de la Unidad de Justicia y Paz de la Ciudad de Montería solicitó imputación y medida de aseguramiento ante el Tribunal de Justicia y Paz de Medellín, por el delito de concierto para delinquir comprendido desde marzo de 1994, hasta el 31 de julio de 2002.

\section{Hacia la Armada Nacional}

En un primer momento es procesado el Infante de Marina Profesional Hildebrando Heredia Hernández, miembro de la Armada Nacional adscrito al Grupo Aeronaval del Caribe. Heredia llevaba 19 años de pertenecer a la institución, momento en el que fue señalado de homicidio agravado en concurso homogéneo y en concurso heterogéneo con toma de rehenes en concurso homogéneo, desaparición forzada en concurso homogéneo y concierto para delinquir agravado. ${ }^{13}$

Mediante la Resolución fechada el 24 de octubre de 2011, la Fiscalía 33 especializada UNDH-DIH resolvió la situación jurídica de Hildebrando Heredia Hernández: ordenó detención preventiva sin beneficio de libertad, decisión apelada por los defensores y confirmada por el superior jerárquico el día 19 de enero del 2012, con la modificación respecto al delito de secuestro para quedar finalmente como toma de rehenes. El 26 de octubre del 2012 el despacho cerró la investigación, calificando el mérito del sumario y dictando pliego de cargos en contra de Heredia como presunto autor responsable de los delitos de homicidio agravado, concierto para delinquir, secuestro simple y desaparición forzada, resolución confirmada por la Fiscalía Octava Delegada ante el Tribunal Superior de Barranquilla.

Las pruebas que el despacho fallador tuvo en cuenta fueron: el acta de necropsia de cada una de las personas que perdieron la

13 Investigación radicada № 13001-31-07-001-201300007 Interno 2013-007. 
vida; actas de levantamiento de cadáver de cada una de las víctimas, declaraciones de testigos durante la masacre ${ }^{14}$; se anexó copia de la declaración de Sergio Manuel Córdoba, alias 'el Gordo', proveniente de la Fiscalía 11 de la Unidad de Justicia y Paz, copia auténtica de la declaración de Orlando Arrieta Catalán rendida ante la Fiscalía 30 de la Unidad de Derechos Humanos de Bogotá, así mismo declaraciones de varios miembros de la Armada Nacional.

En esta misma investigación Hildebrando Heredia Hernández negó en su testimonio ${ }^{15}$ los hechos y que solo se enteró de los mismos por noticias y referencia de los compañeros, por lo que estaría demostrado que tanto él como varios de los integrantes de la compañía militar participaron en los mismos. Esta afirmación también es respaldada en la indagatoria rendida por Sergio Manuel Córdoba Ávila, alias 'el Gordo', el 3 de febrero de 2011, donde asegura que Mancuso envió al Cabo Barreto con las instrucciones de la operación, partieron hacia el Carmen donde se reunieron con la contraguerrilla de la infantería ubicada en una base cercana a El Carmen, al entrar a la base y el cabo le presentó un teniente de apellido Pastrana, y sacó 12 hombres (entre los que se encontraba Hildebrando) que se reunieron con los suyos, y posteriormente salieron hacia Zambrano en 3 camionetas de las autodefensas $^{16}$.

Mediante las declaraciones dadas por el Infante de Marina Jesús Miguel Fadul Atencia, Sergio Manuel Córdoba y Reinaldo Contreras Chamorro se ubicó a Hildebrando Heredia dentro del grupo de 12 hombres de la Fuerza Pública que asistió a dicha masacre. Concluye el despacho que la actuación desplegada no tiene ninguna justificación plausible, ni tampoco la existencia de alguna circunstancia que le impidiera actuar de otra manera, siendo su conducta antijurídica, ya que lesionó los bienes jurídicos tutelados por el legislador, de la seguridad pública, la vida, personas y bienes protegidos por el derecho internacional humanitario y libertad individual y otras garantías. Bajo estas

\footnotetext{
14 José Miguel Bolaño Causado, Marqueza del Socorro Monterrosa Aguas, Betty Simancas Tapia, Álvaro de Jesús Ochoa Ochoa, Martín Alonso Oviedo González, Silfrido Oviedo Velilla, Margel del Socorro Bolaño Sánchez y Gladys Sánchez Barreto.

15 Sentencia del 12 de agosto de 2016 del Juzgado Primero Penal del Circuito Especializado de Cartagena de Indias D.T. Y C. radicado 13001-31-07-001-2013-00007 Interno 2013-007.

16 Ibíd, Juzgado Primero Penal del Circuito Especializado de Cartagena de Indias D.T Y C.
} 
aseveraciones se declaró la responsabilidad penal de Hildebrando Heredia como coautor de los delitos de homicidio agravado en concurso homogéneo y en concurso heterogéneo con toma de rehenes en concurso homogéneo, desaparición forzada en concurso homogéneo y concierto para delinquir agravado en calidad de autor. Se condenó a la pena principal de 473 meses de prisión, multa de 10.044,800067 smlmv e inhabilitación de derechos y funciones públicas por el término de 20 años. Igualmente, se abstuvo de condenar a Heredia Hernández al pago de perjuicios materiales, se condenó al pago de una indemnización por concepto de perjuicio morales a la suma de $62.5 \mathrm{smlmv}$ por familia a los herederos de primer grado de los asesinados y desaparecidos referenciados.

\section{Contexto de la acción}

De acuerdo con declaraciones ${ }^{17}$ del 12 de agosto del 2016, la compañía ‘Tiburón’ venía presentando problemas de indisciplina en patrullajes, evasiones, fuga de materiales, retardos, conflictos internos, entre otros. En la declaración se señala el no tener conocimiento respecto de algún informe que hubiera sido presentado por el Infante de Marina Fadul Atencia respecto de actividades al margen de la ley de la compañía, pues si lo hubiera sabido la compañía hubiese tomado las medidas necesarias. Se presumía que había acciones irregulares al interior de la brigada, y por eso el mando había extremado las medidas de seguridad y de contrainteligencia. Sin embargo, solamente se presentó la denuncia un infante de marina acusando al Capitán Pita de apoyar a un grupo de autodefensas.

Dentro de la misma investigación, el 21 de noviembre de 2001 en otra declaración se señala que en agosto de 1999 el Comandante de la Compañía 'Tiburón' presentó una denuncia ante el Comando del Batallón por amenazas contra su vida, realizadas por el Cabo Barreto. El declarante agregó en su denuncia que el Cabo Barreto era miembro de las autodefensas ilegales y que tenía comunicación por celular con los comandantes de dicha estructura ilegal. El declarante agregó que

17 Sentencia pública del 12 de agosto de 2016 del Juzgado Primero Penal del Circuito Especializado de Cartagena de Indias D.T. Y C. Radicado 13001-31-07-001-2013-00007 Interno 2013-007. 
no tuvo conocimiento sobre los vínculos de los infantes de marina, entre ellos Hildebrando Heredia, con el grupo de las autodefensas ilegales, pero que sí sabía que estos tenían una relación muy cercana con el suboficial Barreto.

El Comandante de la Compañía 'Tiburón' de la época señaló que no tuvo conocimiento de actividades ilegales del Cabo Barreto. Se enteró de los problemas que tenía con él uno de los tenientes, haciendo relación a la amenaza que dicho teniente denunció en su momento. Uno de los Infantes de Marina dio a conocer en la declaración cómo estaba conformada la Compañía Tiburón y señaló que el Comandante del Gil 92, que era en su momento un grupo de inteligencia y localización (que a la fecha no existe), era el suboficial Barreto. El Capitán de Fragata, Gregorio García Raigoza, abrió investigación para averiguar los presuntos nexos de Barreto con grupos de las autodefensas ilegales, por lo que lo relevó del cargo para que no tuviera más contacto ni relación con las operaciones del Batallón. Así mismo, con respecto de la piratería terrestre de algunos infantes de marina, entre estos Hildebrando Heredia, dijo que hubo algunas acciones disciplinarias y revistas a las pertenencias de los infantes en donde se le incautó un arma al infante.

\section{El Salado: 16 al 21 de febrero de 2000}

\section{Hechos}

Entre el 16 y el 21 de febrero de 2000 cerca de 450 miembros de las autodefensas ilegales (cifra aproximada y variable) ingresaron a El Salado, corregimiento de El Carmen de Bolívar ubicado en los Montes de María, donde torturaron y asesinaron a 59 personas (Centro Nacional de Memoria Histórica, 2009: 42). Su propósito era el de desterrar a la guerrilla y a todos los pobladores por sus aseveraciones de colaboración con este grupo armado, y dejar instalado allí un grupo de autodefensas ilegales que controlaran el territorio. El Salado era una zona geográfica estratégica para el transporte de mercancía y explotación extractiva de la tierra.

La noche del 15 de febrero salieron de San Onofre 60 hombres dirigidos por Rodrigo Mercado Peluffo, alias ‘Cadena’ y Úber Bánquet, alias 'Juancho Dique', en dos camiones por la carretera principal que 
conduce a Cartagena. Hacia la madrugada del 16 de febrero se encontraron cerca de Carmen de Bolívar con otros dos grupos de autodefensas ilegales, uno de los cuales venía de Magdalena enviado por Rodrigo Tovar Pupo, alias 'Jorge 40', que estaba bajo órdenes del jefe de la estructura ilegal Luis Robles Mendoza, alias 'Amaury'. El otro grupo venía de Córdoba al mando de Édgar Ariel Córdoba Trujillo, alias 'cinco siete', perteneciente al Bloque Norte. El jefe de toda la operación era Jhon Henao Gil, conocido como 'H2' cuñado de Castaño, cuya principal misión era ingresar a El Salado y recoger todo el ganado que encontraran (Ruiz, 2008, párr. 17).

Una vez reunidos los grupos, planearon la entrada a El Salado por los caminos veredales y por sitios diferentes. Un grupo entraría por la carretera principal de El Carmen; otro por el municipio de San Pedro hacia los corregimientos Canutal, Canutalito y zonas rurales del corregimiento Flor de Monte; otro por el municipio de Zambrano desde la vía que comunica con El Salado; otro por la vía que comunica a El Salado con el casco urbano de El Carmen de Bolívar, y un cierre del cerco que conduce a La Sierra (Centro Nacional de Memoria Histórica, 2009: 25), con un aproximado de 450 hombres $^{18}$.

Al llegar a El Salado, reunieron a todo el pueblo en la plaza junto a la iglesia y con ayuda de algunos desertores de las FARC que señalaban a los guerrilleros, iban cometiendo las primeras ejecuciones, entre las que se encuentra Nayibis Contreras, señalada de tener una relación con Martín Caballero, cabecilla del Frente 37 de las FARC. Mientras realizaban estos actos en tierra, un helicóptero sobrevolaba el pueblo y ametrallaban las casas. Durante cinco días los miembros de las autodefensas ilegales tuvieron el control del pueblo, asesinando y atemorizando a la población. Cada que realizaban una "hazaña" festejaban su triunfo sacando tambores, gaitas y acordeones para hacer un toque, simulando un ambiente de corraleja (Ruiz, 2008).

Al amanecer del quinto día las autodefensas ilegales seguían en el puebloy, pese al temor, los habitantes empezaron a cavar fosas para sus muertos, mientras que los miembros de las autodefensas ilegales

18 El Centro Nacional de Memoria Histórica señala en pie de página que esta cifra es tomada de "Testimonio concedido por Édgar Córdoba Trujillo, alias 'Cinco Siete', a los investigadores de MH en la Cárcel Modelo de Barranquilla el 20 de agosto de 2008. El comandante en cuestión era el segundo mando de la incursión paramilitar, detrás de John Henao, alias 'H2'". 
saqueaban las tiendas, bebían ybailaban. Hacia las 4 de la tarde se escucharon disparos al aire como señal de retirada del grupo, advirtiendo a la población que debían irse y no regresar (Ruiz, 2008). Para el 19 de febrero a las 6 de la tarde, una hora después de que las autodefensas ilegales se retiraron, llegó la Infantería de Marina.

\section{Desarrollo judicial}

Las acciones, decisiones e investigaciones emprendidas en el caso de El Salado se dieron por distintos medios de la justicia nacional, ya que este caso fue de competencia de investigaciones penales, administrativas, disciplinarias, del régimen penal militar y de entes creados para la revisión de los hechos desde la perspectiva de derechos humanos y el derecho internacional humanitario. Muchas de las condenas en las acciones de las autodefensas ilegales fueron acogidas por Justicia y Paz en el marco de la desmovilización durante el Gobierno de Álvaro Uribe Vélez.

El día 21 de febrero, la Fiscalía 43 Delegada de El Carmen de Bolívar ordenó la apertura de la investigación por los hechos ocurridos el 18 de febrero. El 23 de ese mes se dictó apertura de instrucción por parte de la Unidad Nacional de Derechos Humanos de la Fiscalía General de la Nación.

\section{Hacia los actores ilegales}

Del grupo de autodefensas ilegales que incursionó en El Salado conformado por aproximadamente 400 personas, solo se condenaron a 15 de ellas, a las que se les endilgaron las conductas delictivas de violaciones, secuestro, hurto, etc. Sin embargo, finalmente solo fueron condenados por concierto para delinquir y homicidio agravado. De los cabecillas del grupo solo se vinculó a John Henao Gil alias 'H2', que se fugó en el proceso de investigación y nunca fue recapturado. La Fiscalía recuperó información sobre la vinculación de varios cabecillas de las autodefensas al caso, respecto de los cuales no se han iniciado juicios en la justicia ordinaria, ya que estos se acogieron a la Ley de Justicia y Paz, como se hace evidente en el informe de Memoria Histórica: 
Junto a este tipo de información, la Fiscalía contaba también, para la época, con amplia información sobre los principales 'cabecillas' de las Autodefensas que operaban en la región, entre los cuales Carlos Castaño, Salvatore Mancuso Gómez, Rodrigo Tovar Pupo, alias 'Jorge 40', Rodrigo Antonio Mercado Peluffo, alias 'Cadena', y Luis Francisco Robles Mendoza, alias ‘Amaury’. (Centro Nacional de Memoria Histórica, 2009: 28)

De parte de la Unidad de Justicia y Paz se llevaron los procesos frente a las personas que se acogieron a la Ley 795 de 2005. El trámite implica el compromiso del desmovilizado en lo atinente a la búsqueda de la justicia, la verdad y la reparación de las víctimas. En este sistema de justicia especial para la paz, la aplicación de la pena alternativa es máximo de 8 años, sin importar lo confesado con ocasión de su participación como integrante del grupo de autodefensas. La anterior situación se evidenció en la lectura de la sentencia del 20 de noviembre de 2014 de la Sala de Justicia y Paz del Tribunal Superior de Bogotá19.

En dicha sentencia se condenaron 12 personas, entre ellas Salvatore Mancuso y Úber Enrique Bánquez Martínez, alias 'Juancho Dique'. La sentencia indica dos situaciones: en una, las condenas aplicables de conformidad con la legislación penal por 480 meses de prisión, que corresponden a 40 años; en otra, posteriormente el beneficio de suspender a los postulados la ejecución de la pena inicial por una pena alternativa equivalente a ocho años de prisión. Con lo cual, sea dicho de paso, dicha pena no será objetada por la comunidad e instituciones de derecho internacional. Las conductas por las cuales fueron condenados en este proceso corresponden a deportación, expulsión, traslado o desplazamiento forzado de población civil, reclutamiento ilícito, desaparición forzada, tortura en persona protegida, actos de terrorismo, secuestro simple, acceso carnal violento en persona protegida, extracción o contribuciones arbitrarias, hurto calificado, destrucción y apropiación de bienes protegidos, violación de habitación ajena, amenazas, actos sexuales abusivos en persona protegida,

19 Número de radicado 110012252000201400027 , de primera instancia, confirmada por la sentencia de segunda instancia SP 15267 de 2016, radicado $n^{\circ} 46075$, aprobado mediante acta $n^{\circ} 334$ del 24 de octubre de 2016 siendo magistrado ponente el doctor José Luis Barceló Camacho. 
actos sexuales violentos en persona protegida, prostitución forzada o esclavitud sexual, tratos inhumanos y degradantes, experimentos biológicos en persona protegida, aborto sin consentimiento y secuestro extorsivo.

\section{Hacia la Armada Nacional}

Por los actos de El Salado fue acusado el General de IM Rodrigo Quiñones, Comandante de la Primera Brigada de la Infantería de Marina, por omisión y posteriormente fue acusado nuevamente por la masacre de Chengue.

El Juzgado 141 de Instrucción Penal Militar abrió indagación preliminar con el fin de establecer si los miembros de las tropas de la Primera Brigada de Infantería de Marina o personal militar o particular relacionado con la institución incurrieron en acción u omisión que haya implicado la posibilidad de iniciar investigación formal.

El 7 de febrero del 2002, el Juzgado 109 de Instrucción Penal Militar concluyó que de las pruebas realizadas durante la investigación no era posible establecer nexos de los miembros de las Fuerzas Armadas con las Autodefensas Unidas de Colombia, y en tal virtud profirió auto inhibitorio, es decir, que se abstuvo de iniciar el proceso, decisión que fue notificada a la Procuradora Penal Delegada, quien no la recurrió.

El 29 de febrero de 2000 el Procurador del Carmen de Bolívar informó al Procurador General de la Nación sobre los hechos ocurridos en El Salado entre el 16 y el 24 de febrero. El Procurador General de la Nación ordenó la apertura de indagación preliminar disciplinaria el día 30 de marzo de la misma anualidad. El día 25 de julio de 2001 dispuso, de conformidad con los decretos 085 de 1989 y 3548 de 1993, la apertura de investigación contra once miembros de la Infantería de Marina y contra dos miembros de la Policía Nacional. El 28 de agosto de 2003 se elevó pliego de cargos contra cuatro miembros de la Infantería de Marina y el archivo de la actuación contra los restantes funcionarios.

En fallo de única instancia de fecha 23 de diciembre de 2004, se absolvió al General de IM Quiñones Cárdenas y al Teniente Coronel Mantilla Serrano. Por otra parte, impuso sanciones disciplinarias al Coronel Sánchez García consistente en suspensión del cargo por el 
término de 50 días y al Capitán Pita Vázquez con la separación absoluta de las fuerzas militares, la inhabilidad para ejercer funciones públicas por el término de 10 años y la pérdida del derecho de concurrir a las sedes sociales y sitios de recreación de las Fuerzas Militares.

Como parte de la investigación dentro del proceso ordinario se vinculó a varios cabecillas de las autodefensas ilegales y al Coronel de la Infantería de Marina Carlos Alberto Sánchez García, a favor de quien se profirió preclusión de la investigación mediante Resolución del $1^{\circ}$ de febrero de 2008 (Terminación del proceso en su contra). Se vinculó con formulación de acusación al Capitán Pita Vázquez, quien fue condenado por el delito de homicidio el 16 de diciembre de 2011. Esta información está sustentada en el informe de los 15 años de la masacre de El Salado del 20 de febrero de 2015. El Capitán retirado presentó recurso de apelación, que se encuentra en el Tribunal Superior de Distrito Judicial de Cartagena, despacho del señor Magistrado Taylor Ivaldi Londoño Herrera, quien se encuentra en proceso para decidir sobre la apelación. A este caso le hace seguimiento la Oficina de Derechos Humanos de la Fuerza Naval del Caribe.

En sentencia del 30 de noviembre de 2015 del Juzgado Cuarto de Descongestión del Circuito Judicial de Sincelejo ${ }^{20}$, donde fueron demandadas la Nación, el Ministerio de Defensa, la Policía Nacional y la Armada Nacional, se acogieron las pretensiones de los demandantes como miembros de los núcleos familiares de por lo menos 18 personas asesinadas en los hechos. Ungrupo irregular denominado de comandos especiales, conformados por al menos 100 miembros de las autodefensas ilegales ingresó a las vías terrestres, fluviales y aéreas, copó militarmente áreas rurales del municipio de Ovejas, aterrorizó a la población, irrumpió en las casas de sus habitantes, saqueó los establecimientos de comercio y dio inicio a una serie de atentados contra la vida, dignidad y la libertad personal que culminó con la ejecución extrajudicial de al menos 18 personas, que fueron incluidas en dicha demanda administrativa y reconocidas en la sentencia. La demanda fue presentada inicialmente ante el Tribunal Contencioso Administrativo de Sucre, e inadmitida mediante auto de fecha 21 de marzo de 2002, ordenándose a la parte accionante subsanarla. El apoderado

20 Dentro de la Acción de Reparación Directa con Radicado No. 70001-33-31-002-2010-0000594-00 
de los demandantes subsanó la demanda, por lo que se profirió auto admisorio el día 18 de junio de 2002.

Mediante apoderado judicial, la Nación -Ministerio de Defensa - Armada Nacional presentó contestación de la demanda, manifestando su oposición a todas y cada una de las pretensiones de la parte actora, señalando que en los hechos criminales ocurridos entre el 16y 21 de febrero de 2000 no hubo ninguna participación por acción u omisión de la FF.MM., en tanto que la masacre ocurrida es imputable al grupo de autodefensas ilegales que perpetró la ejecución colectiva. Igualmente, destacó que la forma sorpresiva con que actuaron los grupos al margen de la ley, guerrilla o autodefensas ilegales, el uso de armas blancas y contundentes para no llamar la atención de las autoridades que pudieran estar cerca, las pésimas vías de comunicación de la zona, el despoblado y la topografía selvática de la zona, constituían condiciones adversas de caso fortuito o fuerza mayor, para que las fuerzas regulares del Estado puedan ejercer su labor preventiva de seguridad. No es posible que cada ciudadano tenga un soldado o un policía que lo proteja.

En su decisión, la Juez acudió a múltiples elementos de convicción que pasaron por testimonios de testigos de los hechos, documentos, informes de diversas autoridades para contextualizar y destacar situaciones que para ella indicaran fallas en la prestación del servicio. Utilizó el informe del Centro de Memoria Histórica sobre la masacre de El Salado para destacar interrogantes sobre los hechos, como la no detección de 450 hombres de las AUc.

La sentencia destacó las declaraciones ante las instancias penales y disciplinarias del Infante de Marina Alfonso Enrique Benítez Espitia, quien indicó que la Compañía Orca se había encontrado con los miembros de las autodefensas ilegales, tuvieron contacto y se despidieron sin enfrentamientos. La misma sentencia indica que no existe prueba alguna que permita inferir la participación directa de la fuerza pública, pero sí inferir que la incursión no fue sorpresiva, y por el contrario era previsible. Igualmente, señaló que lo sucedido no fue un evento instantáneo, sino que por el contrario se prolongó en el tiempo y durante varios días, lo cual a sus ojos hace extraño el hecho de que ninguna de las bases militares y retenes que hacían presencia en la zona hubiera notado la movilización de camiones y hombres vestidos con prendas militares. 
El despacho indicó que resultó clara la posición de garante del Estado colombiano frente a los derechos de protección y seguridad del individuo, lo cual lo obliga a prestar el cuidado y protección necesarios, como eran la protección de la vida de los habitantes afectados por el accionar de las autodefensas ilegales. No pueden acreditar la imposibilidad de defender a la población, ni adelantar acciones de búsqueda, ni combates con el grupo agresor que se movilizó por la región sin inconvenientes.

Su decisión impuso multas económicas por actos permisivos en detrimento de los derechos humanos, condenó a la presentación de excusas por parte del Gobierno Nacional, los altos mandos de la Policía Nacional y Armada Nacional, a las familias de las víctimas en acto público; condenó al ofrecimiento de tratamientos psicológicos y psicosociales a las víctimas, con énfasis en niños, mujeres y adultos mayores. También ordenó a la Oficina de Restitución de Tierras investigar los posibles casos de despojo de las víctimas. Señala finalmente que si bien el hecho fue generado por un tercero, la muerte de las personas es atribuible a la administración pública por el desconocimiento del deber de protección y cuidado establecido en la Constitución de 1991.

\section{Contexto de la acción}

La acción de la Armada Nacional, en el caso de El Salado, ha generado por parte de organismos internacionales y nacionales críticas y acusaciones que no solo han abarcado el ámbito administrativo, sino que ha trascendido a acciones penales y disciplinarias. Los actos de la fuerza pública solo han contado con la versión de las organizaciones como el Centro de Memoria Histórica y entes jurídicos públicos y privados que son los que han encabezado las acusaciones a esta Institución del Estado, debido al hermético manejo de la información considerada sensible por parte de la Fuerza Pública. A pesar de que la acción de la Armada Nacional ha sido cuestionada en múltiples ocasiones, los argumentos brindados por esta permiten ver la existencia de factores que impedían el tránsito de tropas en los territorios, como la magnitud del territorio a proteger en relación al personal disponible, las dificultades tácticas del terreno y la falta de medios de comunicación e infraestructura. 
Los actos de esta Institución entre el 16 y el 21 de febrero del año 2000 en El Salado tienen diferentes lecturas. Una de ellas es que el ingreso de la Armada en el territorio de los Montes de María se dio 2 días después de la llegada de las autodefensas ilegales. Los Montes de María, zona de difícil acceso en la que se encuentran los corregimientos de El Salado y Ovejas, contaba con la presencia de actores ilegales como lo fueron los frentes 35 y 37 de las Fuerzas Armadas Revolucionarias de Colombia (FARC-EP). Las FARC tenían para ese momento alrededor de 450 hombres, el Ejército de Liberación Nacional (ELN) 130 hombres, facciones reorganizadas del Ejército Revolucionario del Pueblo (ERP) con 60 guerrilleros (Observatorio del Programa Presidencial de Derechos Humanos y Derecho Internacional Humanitario 2003:5-6), y otros actores como el Ejército Popular de Liberación (EPL) que se desmovilizan en los años ochenta y que pasaron a alimentar en su mayoría a los frentes de las autodefensas ilegales de la región. Este juego de factores justificó desde su perspectiva institucional la tardía aparición de los miembros de la Fuerza Pública en el lugar. Entre las razones, se esgrime la ubicación lejana de los batallones cercanos a los corregimientos en el año $2000^{21}$.

El acta de seguridad de la Armada Nacional número oo1-oo del 18 de febrero del 2000 levantada en Sincelejo muestra que lo que se pensaba que estaba pasando en El Salado y Ovejas era un enfrentamiento entre el Frente 37 de las FARC y las AUc. Las actas hablan del desconocimiento de las autoridades civiles y militares de la magnitud de los eventos que estaban sucediendo en el corregimiento y, además, confirmaría que es hasta después de esta reunión que se decide realizar una intervención en el territorio.

Todo lo anterior implica que en este caso no se recogieron las evidencias físicas no testimoniales en el lugar de los hechos de la

\footnotetext{
21 La Primera Brigada de I.M tiene su puesto de mando en la ciudad de Sincelejo (Sucre), así mismo cuenta con dos batallones de Fusileros de I.M, dos batallones de Contraguerrillas de I.M; una base de entrenamiento de I.M y un batallón de Policía Naval Militar. Estas unidades tienen su Puesto de Mando: BPNM21: Cartagena (Bolívar); BAFIM3: Malagana (Bolívar); BACIM33: Malagana (Bolívar); BAFIM5: Corozal (Sucre); BACIM31: Corozal (Sucre); BEIM1: Coveñas (Sucre). BACIM31: Corozal, (Sucre); BEIM1: Coveñas, (Sucre). (Juzgado 4 de descongestión Circuito Judicial de Sincelejo, 2010: 22). Sin embargo, cabe aclarar que la base de entrenamiento de la I.M no era ni es parte de la Primera Brigada de Infantería de Marina, pues son escuelas de formación.
} 
principal masacre (la cancha de baloncesto) donde seleccionaron y asesinaron a 38 personas. La razón es que:

Los sobrevivientes de El Salado, en coordinación con la Infantería de Marina, decidieron cavar fosas comunes para enterrar a los muertos, considerando su avanzado estado de descomposición como consecuencia de la exposición a la intemperie por más de 24 horas. Se cavaron cuatro fosas comunes en las áreas aledañas al parque principal y allí fueron colocados los cuerpos envueltos en hamacas. Una parte de los cuerpos fue enterrada en fosas comunes y otra en el cementerio ubicado en las afueras del casco urbano. (Centro Nacional de Memoria histórica, 2009: 44)

Como consecuencia de lo anterior, no se contó con la información técnica de la escena en relación con otras pruebas no testimoniales. Se debió como mínimo describir e identificar los cadáveres y sus condiciones, es decir, fijar la escena de cualquier manera, sea a través de filmación, fotografía, plano topográfico o cualquier otro medio. Igualmente, se debió recolectar y asegurar todas las evidencias posibles, entre otras, vainillas, proyectiles, fluidos corporales, rastros de sangre, etc.

Esto no sucedió. Implicó la necesidad de hacer investigaciones en la que se cuenta con posibilidad limitada de reconstruir solamente través del testimonio de las víctimas que estuvieron relacionadas con los actos cometidos, con el agravante de que la mayoría de ellas ya habían iniciado el proceso de desplazamiento y aparecieron una vez el paso del tiempo, el vencimiento del miedo a las represalias u otras circunstancias se los permitieron. Respecto a las falencias destacadas anteriormente, se podría indicar una falla estructural en la que cada actor cuenta con suficientes argumentos exculpatorios. Por ejemplo, la Armada y la Policía Nacional no fueron responsables de la investigación forense, sino del tema de seguridad pública; el cті tuvo argumentos lógicos y razonables para la demora en su actuar; los testigos todas las razones para alejarse del lugar de los hechos. Esto implica que la posible falla es estructural y no imputable a los actores.

Entre otros factores, se lista la llegada tardía de los actores estatales para lograr una intervención oportuna y parar el baño de sangre; que la justicia no cumpliera cabalmente con sus obligaciones 
de clarificar y generar bienestar y reparación en las víctimas; que algunos de los miembros de la Armada Nacional no pudieran cumplir técnicamente con su obligación de proteger el territorio, la soberanía y a la población en el país. De su parte, la acción de los investigadores forenses fue nula e insuficiente para lograr dar resultados posteriores que respondieran a la magnitud de los eventos. Esto imposibilitó la obtención de pruebas técnicas respaldadas por profesionales, debido al mal manejo de los cuerpos que borró las evidencias tangibles y limitó la investigación a los relatos y las construcciones colectivas de los hechos entre víctimas y victimarios.

En cuanto a la investigación y acción de la administración de justicia para este caso, es evidente que las sentencias y condenas proferidas no logran reparar los hechos, ya que a hoy existen 15 condenas de la justicia ordinaria, de las alrededor de 450 posibles, desconociendo así los testimonios y relatos de las víctimas afectadas por la masacre. La cuota de verdad se ha logrado de forma más certera con la aplicación de la ley de justicia transicional y premial, que motiva la confesión por medio de incentivos como rebajas de pena y beneficios para los victimarios, "la exclusión por omisión de la verdad", lo que a su vez motivó a los postulados a la aceptación individual de la comisión de todo tipo de delitos y vejámenes en contra de los habitantes de El Salado.

Respecto a la Justicia Penal Militar, el día 7 de febrero del año 2002 el Juzgado 109 de Instrucción concluyó que de las pruebas realizadas durante la investigación no era posible establecer nexos de los miembros de las Fuerzas Armadas con las Autodefensas Unidas de Colombia. En tal virtud, profirió auto inhibitorio, es decir, que a la luz del artículo 458 de la Ley 522 de 1999 del Código Penal Militar se abstuvo de iniciar investigación formal, decisión que fue notificada a la Procuradora Penal Delegada, quien no objetó la decisión, en atención a que en el estatuto penal castrense no se encuentra tipificada la conducta de "colaboración de grupos armados organizados" y el título de "Conductas contra el Derecho Internacional Humanitario" del Código Penal Ordinario aún no entraba en vigencia (entró a regir el 24 de julio de 2001). Por lo anterior y complejidad de los hechos en la Armada Nacional, por intermedio del Comandante del Batallón de Fusileros de I.M. No. 5, se solicita a la Fiscalía General de la Nación la investigación por estos hechos con los resultados conocidos, en donde se estableció que esta problemática no es una política institucional, sino una falla cometida de manera individual. 
Lo anterior no concuerda con las decisiones administrativas $\mathrm{y}$ de organismos internacionales, $\mathrm{y}$ ha dejado entrever que la participación previa y posterior de los miembros de la Armada nacional no se trata de un asunto institucional, sino de una falla cometida de manera individual.

\section{Mampuján: 10 de marzo de 2000}

\section{Hechos}

La madrugada del 10 de marzo del 2000, un mes después de la masacre de El Salado, 60 miembros de las autodefensas ilegales al mando de Rodrigo Mercado alias 'Cadena', uno de los cabecillas del Bloque Montes de María, más 90 hombres pertenecientes al Bloque Norte al mando de alias 'Amauri' y 'Gallo', irrumpieron en el corregimiento de Mampuján, ubicado en el municipio de María La Baja. Los hombres convocaron por la fuerza y mediante amenazas con armas de fuego de uso privativo de las fuerzas militares a la población civil de Mampuján, incluidos niños, ancianos, mujeres, y les ordenaron desplazarse de manera inmediata, a más tardar a la madrugada siguiente, porque de lo contrario les pasaría lo mismo que a los pobladores de El Salado (Corte Suprema de Justicia, Sala de Casación Penal, 34547, 2011).

Como la población civil fue acusada de auxiliar a la guerrilla, y bajo esta afirmación, ordenaron los desplazamientos que iniciaron el 11 de marzo de 2000. Con el objetivo de llegar donde se encontraban los guerrilleros, las autodefensas ilegales retuvieron y amenazaron a siete campesinos para que indicaran el camino a Las Brisas, vía a Yucalito, donde se encontraba el campamento de la guerrilla con la que iban a combatir. Una vez proporcionaron las indicaciones del camino, los campesinos fueron dejados en libertad. Salieron como a las diez de la noche del corregimiento jurisdicción de María La Baja (Bolívar), pasaron por las veredas de Yucal, Yucalito, La Haya y siendo las cinco de la mañana, aproximadamente, llegaron al campamento y no encontraron a los insurgentes.

Rodrigo Mercado Pelufo, alias 'Cadena', dio la orden de matar a varias personas porque supuestamente eran de la guerrilla. Para el efecto, ordena a sus 150 hombres sacar a la población civil de sus casas anunciándose como miembros de las autodefensas, vistiendo 
prendas y portando armas de uso privativo de las fuerzas militares. Los concentraron en una planicie y Rodrigo Mercado Peluffo ordenó la ejecución. Entre otros, participaron como autores materiales Úber Bánquez Martínez alias 'Juancho Dique', y Julio Rafael Navarro Méndez, alias 'Macayepo', quienes cumplieron la orden de 'Cadena' degollando a sus víctimas o utilizando armas de fuego. Tiempo después se comprobó que las $11^{22}$ personas degolladas y quemadas eran campesinos inocentes de la zona.

\section{Desarrollo judicial}

\section{Hacia los actores ilegales}

En la actuación procesal de primera instancia, por esta masacre se suscitaron varias investigaciones contra Edwar Cobos Téllez, alias 'Diego Vecino', y Enrique Bánquez Martínez, alias 'Juancho Dique'.

El 11 de noviembre de 2008, la Fiscalía 11 delegada ante el Tribunal de Justicia y Paz de Barranquilla formuló una imputación parcial de cargos y solicitud de imposición de medida de aseguramiento contra Edwar Cobos Téllez. En la audiencia del 27 de noviembre de 2008, el Magistrado de Control de Garantías formuló imputación e impuso medida de aseguramiento de detención preventiva, decisión apelada por el defensor. La Sala declaró la nulidad de la actuación el 9 de febrero de 2009. En audiencia el 24 de marzo de 2009 el Magistrado de Control de Garantías ordenó medida de aseguramiento que fue impugnada por el defensor y la Fiscalía. Durante el trámite respectivo ante la Sala, la defensa desistió del recurso y esa Colegiatura aceptó el desistimiento.

El 30 de marzo de 2009, la Fiscalía formuló cargos ante el Tribunal de Justicia y Paz de Barranquilla contra Edwar Cobos Téllez, quien aceptó los cargos el 18 de junio del mismo año ante el Magistrado de Control de Garantías de la Sala de Justicia y Paz del Tribunal de

22 Joaquín Fernando Posso Ortega, Alfredo Luis Posso García, José Joaquín Posso García, Wilfrido Mercado Tapia, Gabriel Antonio Mercado García, Rafael Enrique Mercado García, José del Rosario Mercado García, Alexis José Rojas Cantillo, Dalmiro Rafael Barrios Lobelo, Jorge Eliécer Tovar Pérez, Manuel Guillermo Yépez Mercado. 
Barranquilla. Consecuentemente, el proceso fue enviado a la Sala de Justicia y Paz del Tribunal de Bogotá.

El 25 de enero de 2010, la Sala de Justicia y Paz del Tribunal de Bogotá adelantó la audiencia de legalización de cargos, cuya determinación fue impugnada por el defensor de Edwar Cobos Téllez. Sin embargo, cuando el expediente se encontraba en la Corte, el defensor desistió del recurso y este desistimiento fue aceptado por la Sala en auto del 17 de febrero de 2010.

En actuación separada, la Fiscalía radicó, el 19 de noviembre de 2008 ante el Magistrado de Control de Garantías de Barranquilla, un escrito formulando imputación parcial contra Úber Enrique Bánquez Martínez. Dicha audiencia se llevó a cabo el día 25 de noviembre de 2008, donde se formuló imputación y se le impuso medida de aseguramiento, la cual no fue impugnada.

El 26 de marzo de 2009 la Fiscalía formuló cargos ante el Tribunal de Justicia y Paz de Barranquilla contra Úber Enrique Bánquez Martínez, quien los aceptó en la audiencia del 27 de abril de 2009 ante el Magistrado de Control de Garantías de la Sala de Justicia y Paz del Tribunal de Barranquilla. El magistrado ordenó la remisión del proceso a la Sala de Justicia y Paz del Tribunal de Bogotá.

El 9 de junio de 2009 la Sala de Justicia y Paz del Tribunal de Bogotá asumió el proceso contra Úber Enrique Bánquez Martínez y fijó la fecha para la audiencia de control de legalidad de los cargos formulados. Igualmente, extendió invitación a varias instituciones estatales y privadas ${ }^{23}$ con el fin de conocer las investigaciones relacionadas con el bloque Héroes de los Montes de María, Frente Canal del Dique de las Autodefensas.

Entre julio y octubre de 2009 se adelantó la audiencia de legalización de cargos contra Úber Enrique Bánquez Martínez. En la sesión del 15 de julio, el Tribunal consolidó los procesos contra Úber Enrique Bánquez Martínez por referirse a los mismos hechos, y a partir de esa fecha la audiencia de legalización de cargos se tramitó en forma conjunta.

23 Invitó a la Direcciones de Inteligencia del Ejército y la Policía Nacional; Comisión de la Memoria Histórica de la Comisión Nacional de Reparación y Reconciliación; Instituto de Estudios Políticos y Relaciones Internacionales de la Universidad Nacional y Centro de Recursos para el Análisis de Conflictos, Cerac. 
El 29 de junio de 2010, luego de adelantar el incidente de reparación integral, la Sala de Justicia y Paz del Tribunal Superior de Bogotá profirió sentencia de carácter condenatorio contra Edwar Cobos Téllez y Úber Enrique Bánquez Martínez, en su condición de desmovilizados y jefes del bloque Héroes de los Montes de María y Frente Canal del Dique de las Autodefensas Unidas de Colombia, AUc. Los sentenció a 468 y 462 meses de prisión respectivamente, como coautores de los delitos de homicidio agravado; deportación, expulsión, traslado o desplazamiento forzoso de la población civil; secuestro simple; hurto calificado y agravado; utilización ilegal de uniformes e insignias y fabricación, tráfico y porte de armas y municiones de uso privativo de las fuerzas armadas, en concurso homogéneo y sucesivo. A Edwar Cobos Téllez adicionalmente se le condenó por concierto para delinquir agravado. Así mismo, el juzgador de primera instancia determinó suspender a los postulados la ejecución de la pena de prisión por una pena alternativa equivalente a ocho años de prisión, la cual debe cumplirse en centro de reclusión. El representante de la Fiscalía, los dos representantes del Ministerio Público, los trece representantes de las víctimas y los dos defensores apelaron el fallo.

El 26 de julio de 2010, la Sala de Casación Penal de la Corte Suprema de Justicia asumió el conocimiento del asunto y fijó fecha para la audiencia de argumentación oral del recurso, actuación surtida durante los días 9 de septiembre, 4 y 7 de octubre siguientes. El 29 abril de 2011 la Corte Suprema de Justicia leyó el fallo del proceso en contra de los ex jefes del Bloque Montes de María, Edward Cobos Téllez y Uber Bánquez alias 'Juancho Dique', por la masacre de 11 campesinos y el desplazamiento forzado de 300 familias en Mampuján.

Edwar Cobos Téllez fue condenado con una pena principal de cuatrocientos sesenta y ocho (468) meses de prisión y multa de mil quinientos (1500) salarios mínimos legales mensuales vigentes. Úber Enrique Bánquez Martínez fue condenado a la pena principal de cuatrocientos sesenta y dos (462) meses de prisión y multa de mil quinientos (1500) salarios mínimos legales mensuales vigentes. También fueron inhabilitados para el ejercicio de derechos y funciones públicas por un lapso de veinte (20) años. La ejecución de la pena de prisión fue suspendida por una pena alternativa equivalente a ocho (8) años, la pena máxima establecida por el proceso de justicia y paz. Al igual que los demás integrantes del Bloque Montes de María y Frente Canal del Dique de las Autodefensas Unidas de Colombia, fueron condenados al 
pago de los daños y perjuicios materiales y morales para la reparación integral de las víctimas.

En la actuación procesal de segunda instancia llevada a cabo por la Sala de Casación Penal de la Corte Suprema de Justicia, la Magistrada Ponente María del Rosario González de Lemos resolvió, el 27 de abril de 2011, confirmar el fallo de primera instancia con algunas modificaciones como fijar como nueva fecha para realizar la ceremonia de recordación de las víctimas el 10 de marzo de 2012, así como también la implementación de varios mecanismos con el fin de garantizar la reparación integral de las víctimas.

En cuanto a las consideraciones de la Corte Suprema, los apelantes manifestaron su inconformismo en todo lo relacionado a la reparación de las víctimas. La apelación no fue dirigida a la responsabilidad penal de los sentenciados, y por ley le está vedado al superior estudiar aspectos que no fueron impugnados. Se adiciona el numeral 11 a la sentencia, en donde se exime de cualquier antecedente penal y vínculo con organizaciones guerrilleras a las personas que para el 10 y 11 de marzo habitaban los corregimientos de Mampuján y San Cayetano, en especial respecto de las once víctimas del delito de homicidio en la vereda Las Brisas. Con esto se limpia el nombre de las víctimas que perecieron ese nefasto día.

Hacia la Armada Nacional La Sala de Justicia y Paz del Tribunal Superior de Bogotá, en la sentencia condenatoria fechada 29 de junio de 2010, no acogió la solicitud de impugnación para que el Batallón de Malagana pidiera perdón público por su eventual participación en los trágicos sucesos de marzo de 2000 San Cayetano y Mampuján. La Sala no puede atribuir responsabilidad de manera anticipada a este Batallón, sin que las autoridades correspondientes - la Fiscalíaadelanten investigación y establezcan eventuales responsabilidades.

Nuevamente, esa petición de ofrecer disculpas a las víctimas por parte de la Armada Nacional, siendo la obligación más importante en la sentencia el mejoramiento de las condiciones de seguridad en la zona en cuestión, para lo cual se rindió el informe respectivo de cumplimiento dentro de la octava audiencia efectuada por la juez de circuito de ejecución de penas los días 22 y 23 de febrero de 2018 en Cartagena, en donde manifestó que ya no citaría más a la Armada Nacional para la novena audiencia de seguimiento a la sentencia que se efectuará en Bogotá en el mes de septiembre de 2018. 
Por la supuesta desidia de los integrantes del Batallón Malagana, fue solicitado por los apelantes en la actuación procesal de segunda instancia llevada a cabo por la Sala de Casación Penal de la Corte Suprema de Justicia. Al respecto, la Sala confirmó lo decidido en primera instancia y manifestó que es improcedente, ya que el expediente no arroja elementos de juicio alguno que incrimine a la Armada Nacional.

\section{Contexto de la acción}

Mampuján era una zona de suma importancia para las FARC, pues contaba con las vías de comunicación necesarias para conectarse con el mar, además que al estar ubicado entre Cartagena y Sincelejo ciertas actividades delincuenciales eran más fáciles de ejecutar. De su parte, las autodefensas ilegales también generaron intereses directos por el control de esta zona para aumentar su influencia territorial y transportar con facilidad armas y drogas. Así las cosas, "Mampuján es un lugar estratégico porque conecta algunas comunidades aledañas: la comunidad de la Bonga (Palenque de Mahates, Bolívar); la comunidad de la Haya (San Juan Nepomuceno, Bolívar): La comunidad de las Brisas (Marialabaja)..." (Mampuján, 2008:3). Estaba, además y de manera contundente, el propósito de continuar con la consabida repulsión de cualquier indicio guerrillero. Por ende, los sucesos precedidos por las autodefensas ilegales del Bloque Montes de María son, entre otras razones, producto de la persecución a los guerrilleros.

Estos antecedentes generales son los que se relacionan con la acción de las autodefensas ilegales sobre Mampuján, cuando convocaron por la fuerza y mediante amenazas con armas de fuego, algunas de uso privativo de las fuerzas militares, tales como fusiles Galil, AK157, AK47, M6o, R15, FALL (Tribunal Superior del Distrito Judicial de Bogotá, Sala de Justicia y Paz, 2006 80077, 2010).

Las instrucciones eran llegar a los sectores de El Loro y El Tamarindo corregimiento de San Cayetano, jurisdicción de San Juan Nepomuceno (Bolívar), porque había un campamento de la guerrilla. Salieron como a las diez de la noche del corregimiento jurisdicción de María La Baja (Bolívar), pasaron por las veredas de Yucal, Yucalito, La Haya y siendo las cinco de la mañana, aproximadamente, llegaron al campamento y no encontraron a los insurgentes. 
Cabe destacar que antes del desplazamiento, Mampuján, al ser un corregimiento alejado del casco urbano, contaba con una débil presencia del Estado y de la Fuerza Pública. "La poca presencia gubernamental consistía en los docentes de la Escuela Mixta de Mampuján, el relacionamiento con las autoridades aumentó a partir de la instalación y puesta en funcionamiento de servicios públicos como energía eléctrica y telefonía" (Hernández, 2010:91, citado en Lefkaditis, Patrick y Ordóñez Gómez, 2014).

El Batallón de Malagana fue señalado como posible responsable tanto de omisión como de acción o complicidad, de acuerdo con las versiones libres de Edwar Cobos Téllez, alias ‘Diego Vecino’ y Enrique Bánquez Martínez, alias 'Juancho Dique', tomadas en el proceso adelantado en abril del 2011 por parte de la Corte Suprema de Justicia 2011, así como otras versiones libres de víctimas o testigos de la población. Los últimos cuestionan por qué el camión que salió con las autodefensas ilegales una vez cometida la masacre no fue detenido por las fuerzas armadas, si su paso por el frente de las instalaciones de la Fuerza Pública era obligado. En las sentencias de la Corte los acusados no dieron nombres concretos de personal de batallón involucrado en las acciones en contra de los pobladores de Mampuján. El debate sobre esta presunta responsabilidad sigue abierto, pero lo cierto es que no existen condenas en contra de la Armada Nacional, pues en aquella situación de miedo, confusión e incertidumbre generalizados, los testimonios y procesos de memoria brindaron información confusa y poco estimable como pruebas, tal como lo demuestra la no imputación de cargos contra la Armada Nacional.

\section{Chengue: 17 de enero de 2001}

\section{Hechos}

El 17 de enero de 2001, alrededor de las cuatro de la madrugada, una fracción del Bloque Norte de las AUC ingresa al corregimiento de Chengue, a 50 kilómetros de su jurisdicción, el municipio de Ovejas (Sucre). Allí asesinaron a 29 campesinos señalados de colaborar con el Frente 37 de las FARc.

Luego de un corte de luz, los habitantes fueron sorprendidos por más de 60 hombres pertenecientes a la agrupación conocida como 
Héroes de los Montes de María de las Autodefensas Unidas de Colombia (AUC), por una orden dada por Carlos Castaño y bajo el mando de los cabecillas de las autodefensas ilegales Rodrigo Mercado Peluffo alias ‘Cadena', Úber Bánquez alias 'Juancho Dique' y a la cabeza de alias 'Beatriz' o 'la Doctora' o 'la Enfermera'.

Con el rostro cubierto y uniformes de uso privativo de la Fuerza Pública, irrumpieron violentamente en las casas, hicieron llamar a toda la población, fijando la atención en los hombres y buscando de manera particular a 27 de ellos sospechosos de colaborar con las FARC. Entre ellos se listaron líderes comunitarios, el inspector de policía, el maestro de escuela, y en general cualquiera con reputación de autoridad en la comunidad.

Una vez allí, fueron separados en dos grupos: unos arriba de la plaza principal y los otros junto al puesto de salud. Separaron a los hombres de las mujeres y los niños, e hicieron pasar a los hombres con su cédula en mano frente a tres personas del grupo; uno de ellos permanecía sentado en una silla (individuo al que llamaban 'la Computadora') para posteriormente ser masacrados en ese mismo lugar frente a sus esposas, hermanas, tías e hijos. Perpetraron sus crímenes con aplastamiento en la cabeza con el uso de un arma contundente ('mona', que es un martillo grande de hierro), y otros con armas cortocontundentes. Masacraron a 29 personas en la plaza del pueblo, con elementos que no produjeran ruidos, pues a media hora del poblado había una base de la Infantería de Marina y muy cerca se encontraba el Frente 37 de las FARC, y no querían generar ruidos delatores.

Cerca del amanecer, encerraron a las mujeres y prendieron fuego a 25 casas. Se marcharon alrededor de las 6:30 a.m. por la carretera de Macayepo a Chinulito, hasta la finca El Palmar de San Onofre, lugar en el que se planeó el crimen. 


\section{Desarrollo judicial}

\section{Hacia los actores ilegales}

En la actuación procesal de primera instancia, por esta masacre se adelantaron varias investigaciones, entre otras la de Nidia Esther Velilla Pérez, alias ‘Beatriz' o ‘la Doctora’ o ‘la Enfermera'. El 29 de febrero de 2008 la Fiscalía 11 Especializada de la Unidad Nacional de Derechos Humanos y Derecho Internacional Humanitario con sede en Bogotá, acusó a Nidia Esther Velilla como presunta coautora responsable del concurso de delitos de homicidio agravado, concierto para delinquir agravado, incendio, hurto calificado agravado y desplazamiento forzado. La sentencia fue confirmada íntegramente el 12 de junio siguiente por parte de la Fiscalía Trece de la Unidad de Fiscalía Delegada ante el Tribunal Superior de Bogotá, en segunda instancia por la apelación promovida por la defensa. La etapa de juicio fue asumida por el Juzgado Penal del Circuito Especializado de Sincelejo (Sucre), que el 6 de octubre de 2011 emitió sentencia condenatoria.

En la actuación procesal de segunda instancia fue recurrida la anterior decisión por la defensa, pero el Tribunal Superior del Distrito Judicial de Sincelejo por medio del fallo del 27 de abril de 2012 la confirma. Contra esta, el defensor interpuso recurso extraordinario de casación, siendo admitida por la Corte Suprema de Justicia. En decisión del 21 de agosto de 2013 el Magistrado Ponente José Leonidas Bustos Martínez de la Sala de Casación Penal ${ }^{24}$ casa la sentencia y la anula, dándole validez al testimonio de Úber Enrique Bánquez Martínez, alias 'Juancho Dique', quien reconoció que esa mujer no era alias 'la Doctora' o ‘Enfermera'. Precisamente, basándose en ese testimonio, se pudo identificar plenamente a otra mujer: Shirly Luna Díaz, alias 'la Doctora,' 'Beatriz' o 'la Enfermera'. Después de aceptar cargos, en el 2015 el Juzgado Penal del Circuito Especializado de Sincelejo condenó a Shirly a la pena de cinco (5) años y cuatro (4) meses de prisión como coautora de los delitos de concierto para delinquir y desplazamiento forzado.

El Juzgado Penal del Circuito Especializado de Sincelejo, Sucre, emitió sentencia condenatoria el 26 de mayo de 2009 contra Úber

24 Número de radicado 40481. 
Enrique Bánquez Martínez, alias 'Juancho Dique', por los delitos de concierto para delinquir agravado, homicidio agravado, desplazamiento forzado, hurto calificado agravado e incendio. Se hizo por sentencia anticipada, ya que reconoció su autoría en esa masacre.

\section{Hacia la Armada Nacional}

De su parte, mediante Resolución del 16 de abril de 2001 se ordenó la captura del Sargento Rubén Darío Rojas Bolívar, a quien el 4 de mayo de ese mismo año se impuso medida de aseguramiento por el delito de concierto para delinquir. Seguidamente, el 16 de julio se vinculó al Sargento Euclides Rafael Bossa Mendoza y el 26 de julio se le ordenó medida de aseguramiento por los delitos de concierto para delinquir y homicidio. El 14 de marzo de 2002 la Fiscalía 11 de la Unidad Nacional de Derechos Humanos y Derecho Internacional Humanitario (UNDH-DIH) le dictó Resolución de Acusación ${ }^{25}$.En este proceso, mediante decisión del 31 de enero de 2003, se profirió sentencia absolutoria por el delito de concierto para delinquir agravado a favor de Bossa Mendoza. En actuación procesal de segunda instancia (ya que hubo apelación por parte de la Fiscalía), el Tribunal Superior del Distrito Judicial de Sincelejo ${ }^{26}$ confirmó la decisión el 19 de octubre de 2004.

El Sargento Rojas fue acusado de concierto para delinquir. El mismo Juzgado Penal del Circuito de Sincelejo lo absolvió mediante decisión del 12 de noviembre de $2002^{27}$. Dicha absolución fue impugnada por la Fiscalía y la Sala Penal del Tribunal Superior de Sincelejo, quien confirmó la acusación en decisión del 3 de mayo de 2004. La Fiscalía aclaró que no había méritos para vincularlo con la masacre (Revista Semana, “Una tragedia sin fin”, 2002, párr. 11).

La Fiscalía 81 UNDH-DIH ${ }^{28}$ adelantó el proceso contra el Sargento Segundo de Infantería de Marina(r) Wálter Enrique Buelvas Díaz, que

\footnotetext{
25 Radicada con el No. 2002-20009-01-956C en el Juzgado Penal del Circuito Especializado de Sincelejo, Sucre.

26 Sala Penal de Decisión, M.P. Armando Vergara Cárdenas, Acta No. 5 de 19 de octubre de 2004, radicado No. 2002-00005-01.

27 Con radicado No. 2002-00005-00.

28 Con radicado No. 6779 .
} 
a la fecha se encuentra en etapa probatoria. La Fiscalía 33 UNDH-DIH adelantó investigación contra Víctor Manuel Salazar Jiménez, que también se encuentra a la fecha en período probatorio.

De su parte, la investigación contra el General de I.M. Rodrigo Quiñones Cárdenas por el delito de prevaricato por omisión y contra otros miembros de la Primera Brigada de Infantería de Marina (cursada ante la Unidad de Fiscalía Delegada ante la Corte Suprema de Justicia) fue precluida. Posteriormente fue apelada ante el despacho del Vicefiscal General de la Nación y finalmente confirmada, con lo que quedó en firme la decisión. De otro lado, en fallo de única instancia en materia disciplinaria dado por el despacho del Procurador General el 12 de diciembre de 2003, se le declaró responsable disciplinariamente y se ordenó su separación absoluta de las Fuerzas Militares, junto con la inhabilidad de 5 años para ejercer cargos públicos por la conducta omisiva en que incurrió a título de dolo. El 21 de septiembre de 2012 el Consejo de Estado dejó en firme la destitución e inhabilidad para ejercer cargos públicos por el mismo término de cinco años, al encontrarlo responsable de omisión por no ordenar a sus subalternos atacar a las AUC.

En materia disciplinaria, mediante auto del 30 de enero de 2001 se dispuso la apertura de indagación preliminar ${ }^{29}$ a presuntos involucrados; el 2 de agosto de 2001 se formularon cargos y se ordenó el archivo definitivo de la investigación a favor del Capitán de Fragata Víctor Manuel Salcedo Camargo, el Teniente Coronel Miguel Ángel Yunis, el Teniente Coronel Juan Bautista Cárcamo Cale, el Capitán de Corbeta Ramón Gerardo Moncayo y del Teniente de la Policía Nacional Pablo Cruz Delgadillo.

Por otro lado, La Fiscalía 11 UNDH-DIH adelantó la investigación ${ }^{30}$ contra el Coronel de Infantería de Marina Óscar Eduardo Saavedra, Teniente Coronel de Infantería de Marina Camilo Martínez Moreno, Coronel Ricardo Humberto Perico, y Capitán de Fragata César Augusto Saavedra y otros. De los investigados, fueron sancionados con separación absoluta de las Fuerzas Militares e inhabilidad para ejercer cargo público por cinco años, las siguientes personas:

29 Con el número 009-55910-01-2001.

30 Con radicado No. 956 C. 
- Capitán de Fragata de Infantería de Marina Óscar Eduardo Saavedra Calixto, Comandante del Batallón de Fusileros No. 5 de la Infantería de Marina con sede en Corozal, Sucre.

- Capitán de Corbeta de Infantería de Marina Camilo Martínez Moreno, Segundo Comandante del Batallón deFusileros No. 5 de la Infantería de Marina con sede en Corozal, Sucre.

- Suboficial Segundo de Infantería de Marina Rubén Darío Bolívar, adscrito al Batallón de Fusileros No. 5.

- Suboficial Segundo de Infantería de Marina Rafael Euclides Bossa Mendoza adscrito al Batallón de Fusileros No. 5 (solo con separación absoluta de las Fuerzas Militares).

Como esta decisión fue del resorte del despacho del Procurador General de la Nación, solo admitió el recurso de Reposición, el cual fue interpuesto por los defensores de los disciplinados, siendo resuelto el 14 de septiembre de 2004, manteniendo la decisión.

\section{Contexto de la acción}

Hubo una falla eléctrica que dejó al corregimiento sin luz. Bajo estas circunstancias, a las 4:45 de la madrugada llegaron las Autodefensas con la mencionada lista de nombres. El Inspector de Policía Jaime Gutiérrez declaró: "Era una masacre anunciada, la Armada lo sabía todo y no hicieron nada para evitarlo"; dijo también que "tenían a toda su gente en la zona" (Capítulo I: La masacre de un pueblo el $17 \mathrm{de}$ enero de 2001, 2014, párr. 6). Días antes de la masacre un helicóptero militar sobrevoló el territorio, pues es parte del quehacer operativo en el territorio. Si bien lo anterior denota el conocimiento previo de la fuerza pública sobre los hostigamientos o encerramientos que las autodefensas ilegales llevaban a cabo contra la población civil, esto no significa que fuera una respuesta en términos técnico-operativos, pues las alertas no eran precisas y venían de fuentes que no se podían verificar. Hay que tener en cuenta la geografía del territorio, las distancias a recorrer, la disponibilidad de los pies de fuerza (BACIM y BAFIM), la ubicación de Chengue y la generación de alertas de posibles amenazas que se dieron también hacia el sur de la región, lo que suponía información imprecisa para los desplazamientos de la tropa. Chengue no fue el primer punto de alerta: de nuevo, se alertaron de 
posibles ataques hacia el sur de la región y era necesario tomar una decisión de desplazamiento en circunstancias de confusión.

Aquella noche dos policías reportaron ver tres camiones cargados de hombres con uniforme, brazaletes negros y fusiles. Los camiones tomaban la carretera que, en un desvío de la ruta hacia el sur, comunica con Chengue. Según el medio VerdadAbierta.com, los policías se comunicaron urgentemente con sus superiores y estos con los capitanes de la Armada que estaban al mando alrededor de la zona. El coronel Norman Arango, Comandante del Departamento de Policía de Sucre, había apagado su teléfono celular, por lo que al Capitán le tomó más de una hora hacer contacto con el comandante de la Primera Brigada de Infantería de Marina, el General de I.M. Rodrigo Quiñones.

El Contralmirante, que se encontraba a 88 kilómetros al norte (en Cartagena), no tuvo los elementos suficientes para discernir sobre la información brindada por la Policía, argumentado que la información era incompleta y confusa, de nuevo, porque no se detallaba el punto final de la dirección de dicho camión, que se pensaba iba hacia más al sur. Al día siguiente de la masacre sobrevoló el helicóptero de la Armada, y a las 8:45 de la mañana la Policía Nacional del departamento de Sucre informó sobre una posible incursión de las autodefensas en el corregimiento de Chengue, es decir, horas después de que la masacre había sido perpetrada (Capítulo I: La masacre de un pueblo el $17 \mathrm{de}$ enero de 2001, 2014, párr. 7).

Según un testimonio del informante de las autodefensas ilegales Élkin Valdiris, “Los helicópteros sobrevolaron sobre nosotros, porque salimos de Chengue a las seis de la mañana y los helicópteros llegaron a las nueve, cuando ya estábamos saliendo de Macayepo. Ya habíamos tenido tiempo de descansar... Volaron encima de nosotros cuando salíamos de Macayepo"31.

De acuerdo con uno de los copilotos ${ }^{32}$ de las dos tripulaciones que se encontraba en servicio el día de los hechos, fueron alertados de la situación hacia las 8:00 a.m., de forma inmediata acudieron al Centro de Operaciones de la Primera de Brigada de Infantería de Marina No. 1, donde el entonces Contralmirante Rodrigo Quiñones Cárdenas

\footnotetext{
31 Extraído de la declaración juramentada de Élkin Valdiris a la fiscal Mónica Gaitán, rendida el 10 de febrero de 2001. Folio 19 del Cuaderno de anexos No. 5 del proceso Chengue.

32 Entrevista miembro de Aviación Naval, comunicación personal, 4 de enero de 2018.
} 
dio la orden de realizar una verificación aérea sobre información recibida en la madrugada de un posible ataque a la población civil en Chengue. El tiempo de desplazamiento fue de 30 a 40 minutos, ya que se encontraban ubicados en Corozal y Chengue está al norte del municipio. Se desplazaron en dos helicópteros para realizar la verificación -un Bell 412 y un Fennec-, volando sobre los 3000 pies de altura, ya que por motivos de seguridad y protocolarios no era posible estar por debajo de esta altura. Antes de llegar al área general y realizar la verificación recibieron disparos por parte del frente 35 de las FARC, sin dejar ningún herido.

Ya durante el sobrevuelo a Chengue se realizaban permanentes comunicaciones en tiempo real con el Centro de Operaciones de la Brigada. Desde el helicóptero era posible divisar humo negro saliendo de la zona. Una vez se acercaron más al lugar fue posible establecer que era producto de algunas casas que habían sido incineradas en la comunidad. Dado el nivel de altura al que se encontraban no era posible realizar una distinción del personal, aunque evidenciaron movimientos de vehículos camperos saliendo por las diferentes vías veredales de Chengue. Después realizar el sobrevuelo regresan al Centro de Operaciones de la Brigada, donde informan de lo visto y cerca de las 11 a.m. recibieron indicaciones de realizar un segundo sobrevuelo. Como indicó el copiloto, ninguna de las dos aeronaves disponibles para el operativo estaba acondicionada para realizar vuelos nocturnos, y ninguna de las dos tripulaciones presentes tenía el entrenamiento necesario para realizar estos vuelos. Para la fecha de los hechos, no se contaba con el equipamiento necesario (lentes de visión nocturna), ni la preparación para su uso, tanto el personal como la cabina del helicóptero debe contar con las dotaciones y entrenamiento necesario para realizar este tipo de operaciones. Sin embargo, ninguna de estas condiciones era propia para la época.

De otro lado, los fiscales resolvieron la situación jurídica de Íngrid Johanna Guerra Solar, alias 'la Negra'. La primera fue acusada de homicidio con fines terroristas, concierto para delinquir con fines terroristas, incendio, y hurto calificado y agravado. La Fiscalía aseguró que tenía pruebas de su participación plena en la masacre; Elkin Valdiris dice que la vio matar a uno de los campesinos, y en su poder encontraron una prenda de vestir que habían robado las autodefensas ilegales en una de las casas de Chengue ("Una tragedia sin fin”, 2002, párr. 11); sin embargo, en decisión de fecha 5 de septiembre 
de 2002, el Juzgado Penal del Circuito Especializado de Sincelejo la absuelve.

Con la orden inmediata del Contralmirante Quiñonez, se dio el despliegue de sus unidades tácticas de las tropas hacia el lugar con el fin de verificar qué había sucedido en el pueblo del Chengue. La Fiscalía comprobó, por ejemplo, que la Compañía Dragón, con 65 infantes de Marina al mando de un oficial y seis suboficiales estaba localizada en Pijiguay, a una hora de camino de Chengue. Otro grupo, el Cascabel 42, conformado por 33 infantes de Marina al mando de cuatro suboficiales, tenía asiento en San Onofre. La Compañía Dragón fue la primera en llegar al lugar del crimen. Llegaron sobre las 9 de la mañana cuando los perpetradores ya se habían retirado, así como también el helicóptero de la Policía lo hizo después de los hechos. Al tiempo, la respuesta derivó en la instalación de retenes en las posibles vías de escape de los perpetradores de la masacre, el envío de apoyo de dos helicópteros de la Armada Nacional y fue solicitado el apoyo de Fuerza Aérea Colombiana, quienes enviaron 4 helicópteros.

Cuando las tropas ingresaban al área, hubo lugar a un combate que duró aproximadamente dos horas. Una vez las unidades recuperaron el corregimiento de Chengue y durante el registro y control de área, las tropas encontraron inicialmente 23 cadáveres. Así mismo, para evitar ataques a otras poblaciones, las unidades de Infantería de Marina impidieron que el grupo de autodefensas atacara los corregimientos de Salitral y Don Gabriel por medio del despliegue militar necesario.

En el fallo del 2 de agosto del 2001, la Procuraduría determinó que en las horas de la noche del 16 de enero de 2001 algunos miembros de la Policía Nacional vieron pasar por el municipio de San Onofre (Sucre) tres camiones llenos de personal de AUc, que se dirigían a la vía que conduce a Toluviejo (Sucre). El personal de la Policía que recibió el mensaje procedió a trasmitir la alarma tanto a sus superiores como al Teniente Coronel Óscar Eduardo Saavedra Calixto, quien era el Comandante del Batallón de Fusileros No. 5 de la Infantería de Marina con sede en Corozal (Sucre). Sin embargo, al analizar los testimonios citados por la Procuraduría, es evidente que no existía claridad en los reportes de la Policía sobre el presunto personal uniformado.

El entonces Capitán de Fragata Miguel Ángel Yunis, Comandante del Batallón Fluvial de Infantería de Marina No. 3, habló de la situación con el Contralmirante Quiñones. Según un miembro de 
la Armada 33 , sus oficiales reportaron que los datos que recibieron de la Policía Nacional eran incompletos, generales y con muchos vacíos. Pese a ello trataron de confirmarlos y alertaron a las unidades que tenían en la zona, que estaban dispuestas para prevenir el anunciado ataque de las AUc, e hicieron retenes sobre la vía entre San Onofre y Tolú Viejo al considerar que eran los puntos hacia los que se dirigían las AUc, pues era la ruta que la Policía informó en su momento.

La justicia actuó en el caso de la masacre de Chengue en condenas en contra de las autodefensas ilegales, así como en contra de la Armada Nacional, que fueron asumidas de acuerdo con las investigaciones y decisiones de la Fiscalía. Sin embargo, es evidente que los elementos geográficos, de comunicación y de estructura ilegal del territorio (alertas de amenazas terroristas en todos los puntos precisamente con el fin de distraer la acción del Estado) para la época no permitían una operación óptima. El pie de fuerza estaba limitado en número y por ende en las condiciones técnicas reglamentarias para operar no eran las esperadas, así como la información brindada por la Policía no fue clara y por ende las acciones se desarrollaron en el marco de imprecisión y la confusión. También el actuar de las autodefensas ilegales fue estratégico en cuanto a la decisión de no usar armas de fuego que producen un nivel de ruido y posiblemente ser percibido por el pie de fuerza que estaba más cercano.

Esto sin excluir, por supuesto, las responsabilidades y complicidades de algunos miembros de la Armada Nacional, quienes individualmente utilizaron su posición de manera ambigua entre el servicio al Estado, las fuerzas al margen de la ley y sus intereses personales. Hay que recordar que el Gobierno incentivó erróneamente la creación de las Convivir como eje civil armado aliado del Estado, en un marco legal para actuar contra la guerrilla (ver capítulo “Dinámicas de la violencia en Montes de María”). La población civil fue la directamente afectada debido a las estigmatizaciones y a las acciones violentas ejecutadas en su contra.

La justicia actuó en este caso en condenas tanto a los miembros de la Armada Nacional por responsabilidad penal (que es individual y no una postura ideológica institucional) o administrativa (que obedece

33 Conversación con miembro de la Armada Nacional para la época, comunicación personal, 20 de noviembre de 2017. No se revela su identidad, por temas de seguridad y confidencialidad. 
a factores más complejos tanto personales como de posibilidades de recursos y acción en una situación de violencia y amenaza tan intensa), y en condenas en contra de las Autodefensas Unidas Ilegales, que actuaban como un bloque de poder basado en el terrorismo como mecanismo de control.

\section{Apuntes de cierre para la comprensión de los casos}

La región de Montes de María ha sido una de las más afectadas por la violencia en Colombia, pues debido a su posición estratégica fue víctima de la acción de diferentes actores en disputa por el control de un territorio que facilitaba la comisión de actos ilícitos por parte de organizaciones y personas al margen de la ley.

En parte, la geografía permite entender la complejidad de la situación para la fuerza pública. Los Montes de María son una serie de cadenas montañosas discontinuas, que realmente no presentan grandes elevaciones, pero por ser tan irregular reviste dificultad en el control efectivo del territorio por parte del Estado34. La zona alguna vez fue descrita como una hoja de papel que se arruga completamente, para aludir a las dificultades del terreno irregular. Esta situación dificultó la movilidad de los miembros de la Fuerza Pública para ejercer el control efectivo que le corresponde al Estado.

Adicionalmente, la propia figura del Estado requiere ser problematizada en dicho control al que debe su existencia. El Estado colombiano como tipo jurídico que representa un grupo humano que convive en un territorio y que obedece a las mismas reglas normativas y sociales, se ha caracterizado históricamente por el uso legítimo de

34 Los Montes de María se divide en tres áreas: la zona montañosa donde se encuentra enclavada la mayor parte de poblaciones con sus veredas y corregimientos, que son tierras cultivables y productivas, abundante agua durante todo el año, pero con vías terciarias completamente abandonadas, conocidas como las aguacateras; la segunda zona, conocida como Las Aromeras, que comprendía varias poblaciones, entre ellas El Salado, pero realmente es toda el área de la sabana que conforma los Montes de María, es la parte plana de grandes pastizales aptas para la ganadería pero con muy poca agua. Una tercera que es la que está hacia la costa, delimitada por la troncal del Caribe, vía San Onofre-Toluviejo (separación entre los Montes de María y el Mar), distante de la parte montañosa la de mayor afectación para la población civil. 
la fuerza, que en algunos casos ha jugado permisivamente en favor de intereses económicos y políticos que no son los de la sociedad civil.

Lo anterior produjo una respuesta jurídica que ha probado su ineficiencia y consecuencias nefastas. La creación de normatividad para legitimar el uso de la fuerza por parte de particulares y en defensa de intereses privados supuso un claro y poco conveniente desplazamiento del deber de cuidado del Estado: ceder parte de su monopolio de la fuerza a los particulares. Esto derivó en el nacimiento de las Convivir, que a su turno fueron la génesis de las autodefensas.

El fenómeno no solamente es imputable a organizaciones ilegales o a intereses económicos privados, sino a personas individuales de todos los actores que en medio de la situación buscaron provecho personal. La literatura ha discutido ampliamente la insuficiencia de entender la guerra como una cuestión de víctimas y victimarios, o de bandos e instituciones puras, pues la misma configuración de base de las diferentes fuerzas (legales e ilegales) se caracterizó por contar con personas sin ideales políticos o ideológicos superiores, sino motivados por intereses personales (altruistas o egoístas) en los que se movían estratégicamente desde donde les fuera posible.

En una extraña mixtura, la situación de Montes de María contuvo la pugna entre ideologías políticas dibujadas como opuestas y estereotipadas, en donde las ideas de derecha, gobierno, izquierda, grupos al margen de la ley, sociedad civil, interés común e interés particular se confunden y se mezclan según cada lectura. El panorama estuvo también cruzado por intereses económicos derivados de la propiedad de la tierra, pugnas por el poder político local, intereses oscuros de delincuentes comunes dedicados al narcotráfico, entre otras circunstancias.

Concretamente, para las FARc la región de Montes de María era el corredor vital del Bloque Caribe (con el Frente 37y el Frente 35 hacia el centro del país), para la comercialización de droga y armas, y por ser una región ganadera de gran actividad y productividad económica les era muy rentable la extorsión y el secuestro. Utilizando los municipios y corregimientos antes descritos como retaguardia y centro de abastecimientos para lanzar sus actividades ilícitas. De su parte, las autodefensas con sus dos grupos Héroes de los Montes de María, que contenían en la parte alta del territorio a las FARC, y el grupo Canal del Dique, que se encargaba de controlar y comercializar la droga en 
el área de la costa y el Canal del Dique, con su asentamiento principal en el municipio de San Onofre hasta la costa.

La configuración problemática de la región para el periodo permite cuestionar la acción del Estado, de su aparato legal y de justicia, ya que se dio una situación de normalización de la violencia. Lo que se negoció en principio no fue el control del territorio que le correspondía a la Fuerza Pública, sino que ocurrieron escenarios de difícil control debido a la delicada situación de seguridad para todos los actores. En esta pugna, la población fue sometida a las aberraciones descritas, razones por las cuales para los años posteriores el Gobierno cambió su estrategia y orientó su acción hacia la recuperación total del control de Montes de María, con resultados favorables para las instituciones públicas y el rol del Estado.

Por ello, en Colombia no se puede hablar de actores transparentes. Los actores y personas que participaron en los escenarios de violencia dentro del conflicto armado en el país han transitado entre bandos y acciones de víctimas y victimarios. Respondieron a una violencia estructural que ha sido secundada por el aparato institucional a propósito de leyes e incentivos de doble filo, pero también motivaciones individuales en una región en donde parecía sencillo hacer dinero, tener poder y además mantenerse estratégicamente ubicado de un lado u otro. Jugaron, entonces, múltiples intereses políticos y económicos tanto estructurales como personales. Consecuencia de ello son los fallos producidos por el aparato jurídico ordinario y especial diseñados para los procesos de verdad, justicia, reparación y no repetición. En el caso de la Armada Nacional, las masacres documentadas produjeron los resultados expuestos anteriormente en cada caso en términos de procesos judiciales imputados a personas.

Como se pudo apreciar en la reconstrucción judicial de los casos, la justicia tuvo la tarea de encontrar responsabilidades civiles, penales, administrativas y disciplinarias (es decir, de individuos como de instituciones), por medio de la reconstrucción histórica de los casos, especialmente desde los testimonios dados por los cabecillas y personas involucradas en las autodefensas ilegales. Aunque los documentos de los diferentes organismos de justicia reportan responsabilidades individuales así como procesos administrativos para la reparación en cabeza de las entidades de la Fuerza Pública, no es posible concluir de manera contundente que la acción ilícita 
haya sido promovida como un bloque institucional por parte de la Armada Nacional. Esto no niega la percepción de ciertos integrantes de la Armada Nacional sobre la existencia de un enemigo común, las FARC $^{35}$. La Armada Nacional debía controlar el territorio en medio de un complejo panorama de violencias, grupos armados ilegales, marco legal de las Convivir, informaciones confusas y una capacidad operativa insuficiente.

Esto es posible sostenerlo, pues la Armada Nacional rindió a su turno los resultados que como fuerza del Estado le eran reclamados. Así,

[...] en el período señalado la Armada Nacional llevó a cabo un conjunto de operaciones que impactaron en las estructuras de los grupos de autodefensa y sus finanzas. Una serie de allanamientos, persecuciones y trabajos de inteligencia llevaron a que se decomisaran más de 3.5 toneladas de cocaína en el golfo de Morrosquillo en menos de un año. Se dieron también las primeras capturas, entre ellas la de El Oso, uno de los lugartenientes de Cadena. [...] sólo en el año 2004, fueron dados de baja 30 miembros de las autodefensas, y según Vecino, más de 300 hombres que hacían parte de los frentes bajo su mando fueron capturados. (Fundación Seguridad y Convivencia, s.f.: 5)

El contexto de violencia de la región arrojó condenas y sanciones disciplinarias puntuales imputables a individuos y no a instituciones para el caso de la Armada Nacional, y condenas administrativas a la Armada Nacional por la posición de garante del Estado, así como denuncias por parte de organizaciones internacionales que han sido admitidas y están en proceso. Aunado a lo anterior, la presencia de la justicia premial ha abierto una puerta que permite a un acusado recibir una pena alternativa dentro del marco de las leyes de justicia y paz, que no varía pese a ser condenado por uno o cien hechos delictivos y que en la práctica puede convertirse en un mecanismo

35 En este conflicto siempre estuvo inmersa la población civil, quien al verse en medio de ambos bandos optaba por servir a la organización que ejercía control territorial en el momento, sin que esta significara una vinculación, para así conservar su integridad personal y familiar. 
de manipulación de la verdad con fines extorsivos o de defensa de intereses particulares.

Cabe resaltar además que los actos por los cuales ha sido señalada la fuerza pública, han contado mayoritariamente con la versión y perspectiva de las organizaciones nacionales y entes jurídicos públicos y privados que son los que han encabezado las acusaciones a esta institución del Estado en temas de memoria y responsabilidad. Por ello este libro y este capítulo permiten ampliar las voces y las miradas al conflicto y sus actores, y hacer real y no solo teórica la premisa de la necesidad de desdibujar la visión polar de buenos y malos, instituciones corruptas y personas individuales por fuera de la normativa. Todo esto reforzado por el hermético manejo de la información por parte de la Fuerza Pública y de sus integrantes para la época de los hechos, quienes con sobradas razones evitan dar testimonios e información que puede ser utilizada en su contra, dado el carácter de delitos de lesa humanidad e imprescriptibles con que cuentan las masacres analizadas, dado el marco en el que opera esta justicia especial.

Es indispensable generar un análisis de estas en relación con la capacidad de armamento, logística y de personal de ambos actores, así como las relaciones que se tejieron entre ambas, como se discutió puntualmente en cada uno de los casos. La tropa era insuficiente ante la amenaza de los grupos delictivos, el territorio complicaba la operación en ese entonces en el que no se contaba con la misma tecnología y capacidad de movilidad que hoy se da por cierta, ni tampoco con la capacidad de generar reportes tal como es posible hoy. Sin historizar el hecho técnico y tecnológico en relación con los fallos de la justicia no es posible construir memoria desde las diferentes perspectivas. ¿Cómo actuar y bajo qué criterios poner en riesgo la vida de los integrantes de la Fuerza Pública en condiciones que no permiten asegurar el éxito de la acción? Justamente esa fue una de las directrices del Plan Colombia y de las políticas de gobierno que sucedieron luego de la fatalidad de estas masacres.

No hay que desestimar tampoco la poca aceptabilidad que tuvo la población hacia las fuerzas del Estado, debido a la influencia ideológica y coercitiva que cada uno de los grupos armados ilegales tuvo, de acuerdo a consignas que profesaba a su acomodo. Esta situación también mejoró a partir de la implementación de algunos de dichos planes de gobierno orientados a la seguridad de la población y la mejora en las vías de comunicación, pues dichos planes contribuyeron a recobrar 
la legitimidad del Estado y a emprender un proceso de recuperación de la región.

Adicionalmente, la efectiva presencia institucional, más que proyectar una imagen positiva de sí misma, debe permitir el mejoramiento de la calidad de vida de los habitantes y la reparación integral de las víctimas. Ellos son la principal razón del Estado y sus instituciones, pues como consecuencia del conflicto vivieron un cambio estructural marcado por el deterioro de todo el tejido social del territorio, en el que la Fuerza Pública tuvo parte de responsabilidad (no excusable en tanto garante por parte del Estado), como la tuvieron los demás actores del conflicto. Sin embargo, la institución nunca se alejó de su papel en la verdad y aceptó y visibilizó las condenas de todo tipo que tuvieron lugar, acogió y realizó las acciones administrativas que le fueron impuestas, profundizó en la aplicación del enfoque de derechos humanos que para la época era aún difuso y poco claro en la práctica, con el fin de mejorar con institución al servicio de la ciudadanía.

Finalmente, permitir la discusión con un documento de esta naturaleza que deja tantas preguntas como caminos para la clarificación es una acción directa para que la Armada Nacional visibilice un proceso de memoria y de voz pública abierta a las críticas y lecturas que sean posibles para la construcción polifónica de la verdad.

\section{Referencias}

‘Caracortada' todavía pone a llorar a los Montes de María. (s.f.). La Verdad Abierta. Recuperado de http://www.verdadabierta.com/justiciay-paz/1987

Centro Nacional de Memoria Histórica. (2009). La masacre de El Salado: esa guerra no era nuestra. Colombia. Disponible en: http://www. centrodememoriahistorica.gov.co/descargas/informes2009/informe_la_masacre_de_el_salado.pdf

Corte Suprema de Justicia, Sala de Casación Penal. (27 de abril de 2011). Sentencia de Segunda Instancia 34547. [M.P. María del Rosario González de Lemos].

Comisión Interamericana de Derechos Humanos. (2007). Masacre de Chengue. Colombia.

Consejo de Estado (9 de julio de 2014). Sentencia 44333. 
Departamento Nacional de Planeación. (2016). Plan Colombia: balance de los 15 años.

El paramilitar Salomón Feris Chadid: “El Señor de Santa Fe Ralito”. (2008, 22 de abril). Agencia de Prensa Rural. Recuperado de http://prensarural.org/spip/spip.php?article1188

Fundación Seguridad y Convivencia. (s.f.). Desmovilización del Bloque Héroes de Montes de María de las AUC.

Justicia y Paz 46.075, Sentencia de Salvatore Mancuso. [M. P. José Luis Barceló Camacho]. Sentencia SP15267-2016. Radicación N 46.075 Aprobado acta N 334. Bogotá, D. C. 2016.

Juzgado Primero Penal del Circuito Especializado de Cartagena de Indias D.T. Y C. (12 de Agosto de 2016) Radicado 13001-31-07-001-2013-00007 Interno 2013-007 procesado, Hildebrando Heredia Hernández.

Juzgado Penal del Circuito Especializado, Sincelejo, Sucre (7 de junio de 2002). Radicado No. 2001-00034.

Juzgado Penal del Circuito Especializado de Sincelejo, Sucre. Radicado No. 2002-20009-01-956C.

Juzgado Cuarto de Descongestión del Circuito Judicial de Sincelejo (30 de noviembre de 2015). Radicado No.70001-33-31-002-2010-0000594.00.

La masacre de Pichilín (Sucre). (s.f.). La Verdad Abierta. Recuperado de http://www.verdadabierta.com/victimarios/560la-masacre-de-pichilinsucre

La masacre de El Salado (Semana). (s.f.). La Verdad Abierta. Recuperado de http://www.verdadabierta.com/victimarios/435-lamasacre-de-el-salado-

"La masacre de un pueblo el 17 de enero de 2001" (Capítulo I). (2014, 10 de junio). La Verdad Abierta. Recuperado de http://www.verdadabierta.com/masacres-seccion/5349-capitulo-i-la-masacre-de-unpueblo-el-17-de-enero-de-2001

Lefkaditis, Patrick y Ordóñez Gómez, F. (2014). El derecho a la reparación integral.En Justicia y Paz.El Caso Mampuján, Las Brisas y Veredas de San Cayetano. Bogotá:Instituto para una Sociedad y un Derecho Alternativos - ILSA.

Masacre de Capaca. (s.f.). Rutas del Conflicto. Recuperado de http://rutasdelconflicto.com/interna.php?masacre $=197$

Observatorio del Programa Presidencial de Derechos Humanos y Derecho Internacional Humanitario (2003). Panorama actual de la región de Montes de María y su entorno. IsSN 1657-818 X Serie Geográfica No. 19. Bogotá. 
Reyes, O.C. (2011). El reto de la consolidación en Montes de María: la aplicación de la seguridad democrática a nivel regional. Bogotá: Pontificia Universidad Javeriana.

Ruiz, M. (30 de agosto de 2008). Fiesta de sangre. Semana. Recuperado de http://www.semana.com/nacion/articulo/fiesta-sangre/94863-3 Sala Penal de Decisión (19 de octubre de 2004). Radicado No. 2002-0000501 [M.P. Armando Vergara Cárdenas].

Tribunal Superior del Distrito Judicial de Bogotá, Sala de Justicia y Paz (29 de junio de 2010). Sentencia 200680077 [M.P. Uldi Teresa Jiménez López].

Tribunal Superior de Distrito Judicial de Sincelejo Sala Penal (29 de mayo 2003). Sentencia de segunda instancia. Radicado 2001-00034-01.

Tribunal Superior del Distrito Judicial Sala Penal de Decisión de Sincelejo, Sucre (19 de octubre de 2004). Radicado No. 2002-00005-01 [M.P. Armando Vergara Cárdenas].

Una tragedia sin fin. (3 de noviembre de 2002). Semana. Recuperado de www.semana.com/nacion/articulo/una-tragedia-fin/49947-3

Universidad de San Buenaventura. 2008. “Mampujan”. Documento de recuperación de memoria histórica. Cartagena. Documento sin publicar. 